\title{
Sedentary behaviors and anxiety among children, adolescents and adults: a systematic review and meta-analysis
}

\author{
Bartlomiej Stanczykiewicz ${ }^{1 *+} \mathbb{B}$, Anna Banik ${ }^{2 \dagger}$, Nina Knoll3 ${ }^{3}$ Jan Keller ${ }^{3}$, Diana Hilda Hohl ${ }^{3}$, Joanna Rosińczuk ${ }^{1}$ and \\ Aleksandra Luszczynska ${ }^{2,4^{*}}$
}

\begin{abstract}
Background: Although the number of studies examining the relationships between sedentary behaviors (SB) and anxiety is growing, an overarching evidence, taking into account children, adolescents, and adults as well as different types of SB and different categories of anxiety outcomes, is still missing. Thus, this systematic review and meta-analysis aimed at obtaining a comprehensive overview of existing evidence.

Methods: A search in the following databases: PsycINFO, PsycARTICLES, Academic Search Complete, ERIC, HealthSource: Nursing/Academic Edition and MEDLINE, resulted in $k=31$ original studies included in the systematic review (total $N=99,192$ ) and $k=17$ (total $N=27,443$ ) included in the meta-analysis. Main inclusion criteria referred to testing the SB--anxiety relationship, the quality score (above the threshold of 65\%), and the language of publications (English). The study was following the PRISMA statement and was registered at PROSPERO (CRD42017068517).

Results: Both the systematic review and meta-analysis indicated that overall average effects were small: higher levels of symptoms of anxiety were associated with higher levels of SB (weighted $r=.093,95 \% \mathrm{Cl}[.055, .130], p<.001$ ). Moderator analyses indicated that trends for stronger effects were observed among adults, compared to children/ adolescents $(p=.085)$.
\end{abstract}

Conclusions: Further longitudinal studies are necessary to elucidate the predictive direction of the anxiety - SB relationship and to clarify whether the effects depend on the type of anxiety indicators.

Keywords: Anxiety, Sedentary behaviors, Children, Adolescents, Adults, Systematic review, Meta-analysis

\section{Background}

Sedentary behavior $(\mathrm{SB})$ is reflecting the low end of physical activity and may be placed between sleep and light activity on the movement and energy expenditure continuum [1]. SB involves low levels of energy expenditure (1.0 to 1.5 of metabolic equivalent of task [MET]), usually occurring while sitting, during work or leisure activities, including screen behaviors (e.g., TV watching),

\footnotetext{
* Correspondence: bartlomiej.stanczykiewicz@umed.wroc.pl;

aluszczy@uccs.edu

${ }^{\dagger}$ Bartlomiej Stanczykiewicz and Anna Banik contributed equally to this work and share the first authorship jointly.

'Department of Nervous System Diseases, Wroclaw Medical University, Bartla 5 Street, 51-618 Wroclaw, Poland

${ }^{2}$ Wroclaw Faculty of Psychology, SWPS University of Social Sciences and Humanities, Ostrowskiego 30b Street, 53-238 Wroclaw, Poland Full list of author information is available at the end of the article
}

hobbies (e.g., reading books), lying down, in transit, or during driving a car [1-3]. SB may be operationalized as the total sitting time per day and measured with self-report or objective methods such as accelerometry [4, 5]. An alternative approach to operationalize SB would be to focus on a specific type of SB, such as total screen time [6]. The conceptual model by Biddle, Pearson, and Salmon [7] suggests that $\mathrm{SB}$ research should account for two types of SB, namely total sitting time and total screen time, because these two types of SB form different associations with health outcomes. Subtypes of SB may also be distinguished [8]: for example, total screen time can be divided further into TV watching, computer using, etc.

Recent studies on the prevalence of SB showed that children and adolescents (aged 5-18 years) as well as older adults (aged $60 \geq$ years old) spend between $40 \%$

(c) The Author(s). 2019 Open Access This article is distributed under the terms of the Creative Commons Attribution 4.0 International License (http://creativecommons.org/licenses/by/4.0/), which permits unrestricted use, distribution, and reproduction in any medium, provided you give appropriate credit to the original author(s) and the source, provide a link to the Creative Commons license, and indicate if changes were made. The Creative Commons Public Domain Dedication waiver (http://creativecommons.org/publicdomain/zero/1.0/) applies to the data made available in this article, unless otherwise stated. 
and $60 \%$ of their time sitting $[9,10]$. High levels of SB may increase the risk of mortality and morbidity, independently of the levels of moderate-to-vigorous physical activity [11-13]. SB is associated with an increased risk of chronic physical health problems, including cardiovascular diseases, diabetes, and obesity $[7,14]$. There is also a growing body of evidence suggesting associations between SB and mental health issues, including increased levels of anxiety $[15,16]$. However, there are several open questions regarding associations between SB and anxiety symptoms, which could be clarified in an overarching synthesis of existing evidence. In particular, it is unclear how strong the SB-anxiety relationship is, if this association depends on the type of SB (e.g., total sitting time vs. total screen time), individual's age or health status [16-18]. The present study attempts to clarify these issues.

Anxiety disorders rank among the most common psychiatric disorders with a lifetime global prevalence estimate of $7.3 \%$ (95\% CI [4.8, 10.9\%]) [19]. One in 14 people suffer from anxiety disorders around the world and one in nine (11.6, 95\% CI [7.6, 17.7\%]) will have an anxiety disorder in a given year [19]. Anxiety symptoms are common in diverse populations and feature excessive anxiety-linked emotional and behavioral disturbances as well as associated cognitive ideation [20]. Anxiety is a complex phenomenon involving state and trait components, defined as immediate emotional and somatic reactions to perceived demands and threats and stable inter-individual differences in tendencies to react in such a manner across demanding or threatening situations [21]. Anxiety symptoms occur across the lifespan, with anxiety disorders mostly developing before the age of 35 [22]. The median age of onset was established at 11 years old [23]. There are well-established associations between anxiety symptoms and an increased likelihood of metabolic diseases, cardiovascular incidents, cardiac mortality, diabetes, and stroke [24-27].

The links between SB and anxiety may be explained with physiological and psychological mechanisms. Experimental laboratory and real-life studies indicated that regular physical activity alters physiological responses to stressors which, in turn, affect anxiety levels [28-30]. Physiological pathways involve changes in central catecholamine systems and opioid mechanisms [30]. Additionally, serotonergic pathways may explain links between energy expenditure behaviors and anxiety symptoms. For example, activation of the $5-\mathrm{HT}_{2 \mathrm{C}}$ receptor may elicit an anxiety-like response [31] whereas engaging in physical activity may decrease sensitivity of this receptor and thus reduce anxiety [32]. Psychosocial mechanisms linking anxiety and SB are suggested by the displacement hypothesis, proposing that SB displaces time available for other social and physical activities. It may be expected that several subtypes of screen-based SB, such as TV watching or playing video games, involve little social interaction or limit direct social interaction that influence mental health outcomes, including anxiety [33]. The displacement of physical activity with $\mathrm{SB}$ is associated with less favorable health outcomes [34]. Another psychosocial pathway linking SB and anxiety involves low self-esteem. People with low self-esteem may find physical and active social activities challenging, anxiety-evoking, and taxing, therefore they may be inclined to increase SB in leisure time [35].

Previous systematic reviews provided a preliminary synthesis of evidence for the relationship between SB and anxiety [18]. In particular, a review [18] of 9 studies concluded that the majority of research suggested a positive association between SB and anxiety. The number of studies has been growing in the recent years and a synthesis of findings, accounting for operationalization, measurement heterogeneity (e.g. different types of SB, such as total sitting time vs. total screen time vs. TV watching), and population heterogeneity (children/adolescents vs. adults; people from general population vs people with a chronic illness), is still missing. A meta-analytic approach may allow for a further synthesis of existing evidence and an investigation of the moderating role of the sources of heterogeneity.

Different types of SB may exert different effects on anxiety and anxiety symptoms, yet the evidence is inconclusive. For instance, a review of findings obtained in nine studies on the SB-anxiety symptoms association concluded that there is sufficient evidence for the link between total sitting time and anxiety, whereas the evidence for total screen time and the subtypes of screen time (TV watching, computer use) is inconsistent [18]. In contrast, findings from a recent meta-analysis suggested that the total sitting time is unrelated to anxiety, whereas total screen time as well as its subtype, TV watching, are related to anxiety [16]. However, the conclusions formed in previous reviews are preliminary as they are based on a very limited number of studies (e.g., $k=2$ for total sitting time, $k=4$ for total screen time, $k=3$ for TV watching, [16]).

Theories, such as the socio-ecological approach, suggest associations between SB and socio-demographic factors, such as age [36-38]. For example, the Systems of Sedentary Behaviors framework [39], indicates that the link between SB and its psychosocial correlates (including anxiety or other mental health indicators) may be further moderated by age, with larger effects expected in older samples. Research on SB and its health outcomes usually targeted either samples from children/adolescent populations [40] or older-adult populations only [36, 41], thus the moderating effects of age remain unclear. Consequently, we investigated whether the strength of SB-anxiety relationship may depend on participants' age group. 
Additionally, although research on the $\mathrm{SB}$-anxiety relationship was conducted among people with a chronic physical or mental illness, and in samples recruited from the general population, the effect of health status on SB-anxiety associations is still unclear [18]. A decline in health (or a chronic illness) may have an impact on the relationship between SB and anxiety symptoms [42]. Motl et al. [42] suggested that SB, illness-related physiological processes, and structural impairments are closely related: a combination of these factors may lead to a further decline in health and disability, but also to negative affective states [42]. As research usually focused either on people with a chronic illness or on the general population [43], the moderating effect of a chronic illness was rarely considered.

Our study aimed to summarize the evidence for the SB--anxiety relationship. We conducted a systematic review and meta-analysis in order to: (1) synthesize the associations between $\mathrm{SB}$ and anxiety symptoms and (2) examine if SB-- anxiety associations are moderated by the age group (children/adolescents vs. adults), participants' health status (general population vs. people with a chronic physical or mental illness). Additionally, as the type of SB as well as SB operationalization and measurement may affect associations between SB and its health outcomes [44], we tested the moderating effects of the type of SB (total sitting time vs. total screen time), the subtype of total screen time (i.e., TV viewing vs. computer using vs. computer/video or console games playing), and SB measurement (self-report vs. objective measurement).

\section{Method}

This study followed PRISMA guidelines [45] for systematic reviews and was registered with PROSPERO database (no. CRD42017068517).

\section{Search strategy}

A systematic search of relevant studies published since the inception of the databases until April 2018 was conducted using: PsycINFO, PsycARTICLES, Academic Search Complete, ERIC, HealthSource: Nursing/Academic Edition and MEDLINE. To minimize bias, two researchers ( $\mathrm{BS}$ and $\mathrm{AB}$ ) independently performed an online search for peer-reviewed papers using the following combination of keywords: ('sedentary beh"' OR 'sedentary"' OR 'sitting' OR 'screen"' NOT 'screening' OR 'screen time' OR 'screen-based' OR 'computer games' OR 'video games' OR 'television viewing') AND ('mental health' OR 'mental"' OR 'panic disorder' OR 'anxiet"' OR 'phobia' OR 'worry' OR 'worr"'). This strategy yielded 12,288 records (see Fig. 1; PRISMA flow chart). Studies were included if the keywords were present in either the title, or the abstract, or the original keywords of the paper. After identification of records through database searching, all duplicates $(k=$ 7570) were removed. Additionally, the reference lists of selected studies and the related systematic review [18] were screened to identify relevant articles. Next, two independent researchers ( $\mathrm{BS}$ and $\mathrm{AB}$ ) read abstracts, keywords, and titles in order to establish if the paper reported an original study accounting for the associations between $\mathrm{SB}$ and anxiety. In case the abstract did not provide sufficient information to determine if the paper should be excluded, the researchers followed with reading the full-text. This strategy resulted in excluding $k=7481$ entries: reviews, qualitative research, and quantitative studies which mentioned either anxiety or SB but did not assess these constructs. Next, 89 full-texts were assessed for eligibility (i.e., reporting a statistical test for the association between SB and anxiety). A total of 31 eligible studies were included and analyzed in the systematic review, with 17 studies included into the meta-analysis.

\section{Inclusion/exclusion criteria}

Details of the selection processes are shown in Fig. 1. Overall, the selection process aimed at identifying any original studies determining the associations between SB and anxiety among children, adolescents, and adults of any age.

The main inclusion criteria were: (1) the relationship between SB and anxiety was reported, (2) SB was assessed with either self-report instruments (e.g., International Physical Activity Questionnaire; IPAQ) or an objective measure (e.g., accelerometer), (3) anxiety was measured quantitatively, without restrictions referring to the type of anxiety disorder or its stage (i.e. acute vs. chronic) or duration of anxiety symptoms, and (4) the quality assessment of the study, conducted with the tool by Kmet et al. [46], resulted in a score of at least $65 \%$ (for thresholds, see [46]). Only studies published in English in peer-reviewed journals were included. The decision to include only English-language publications was based on the results of a previous review of 303 meta-analyses [47] which showed that excluding trials published in languages other than English has little effect on the estimated of the effects. Publications in languages other than English were also likely to produce findings which may be more biased, as they included fewer participants, were more likely to produce significant results, and tended to have lower methodological quality than English-language publications [47].

The following exclusion criteria were applied: (1) studies measuring SB that occurred due to internet addiction or pathological internet use but excluding other types of SB, (2) studies accounting for anxiety as an undistinguishable subcomponent of broader constructs and measures, such as psychological distress or quality of life, (3) research with no adequate measure of SB (e.g., indicating only the presence/absence of a specific type of $\mathrm{SB}$ ), and (4) research with populations with severe mobility limitations (and thus with extremely limited variability in 


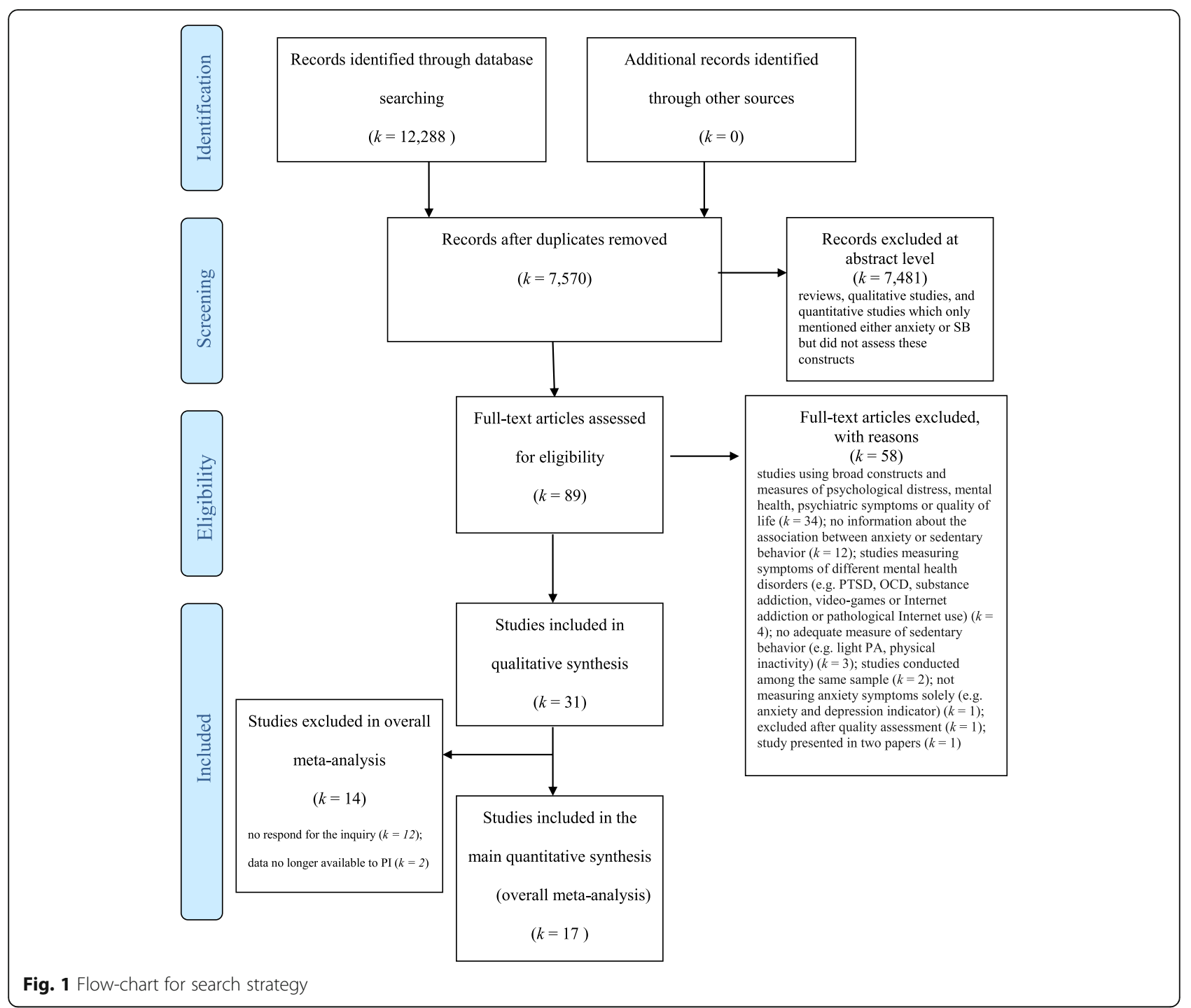

sedentary time). In case the results from one and the same study were presented in two papers, the study with a larger sample or a more recent publication was selected.

\section{Data extraction and quality assessment procedures}

Data extraction (see Table 1) was conducted independently by two researchers (BS and $\mathrm{AB}$ ). Extracted data included details of SB and anxiety measurement, sample characteristics, and main findings of the original study. Selected statistical information and data necessary to conduct the quality evaluation were also retrieved. Any discrepancies during the process of data extraction and quality evaluation were resolved by a consensus method $[48,49]$, involving discussions between two researchers $(B S, A B)$, and the third researcher $(\mathrm{AL})$. In particular, in case of a discrepancy between two researchers (BS and $A B)$, the third researcher (AL) retrieved respective data, conducted the quality evaluation independently, and led the discussion aiming at reaching a consensus. In case the data required to conduct meta-analysis were not included in the original paper, the research team attempted to contact authors via e-mail and requested the required data.

To evaluate the quality of identified studies, a tool by Kmet et al. [46] was applied. This tool for quality determination addresses the following criteria: the clarity of research objectives; the description of study design, participants, measures, randomizations, blinding, the selection of outcomes, rationale for the sample size and analytic method, estimates of variance reported for the main results/outcomes, a control of analyses for confounding effects; reporting results in sufficient detail. Each component was rated using a 3-point response scale ( 2 points for 'yes', 1 point for 'partial', 0 points for 'no'). If the criterion was not applicable for a study, then its score was excluded from the computation of the 


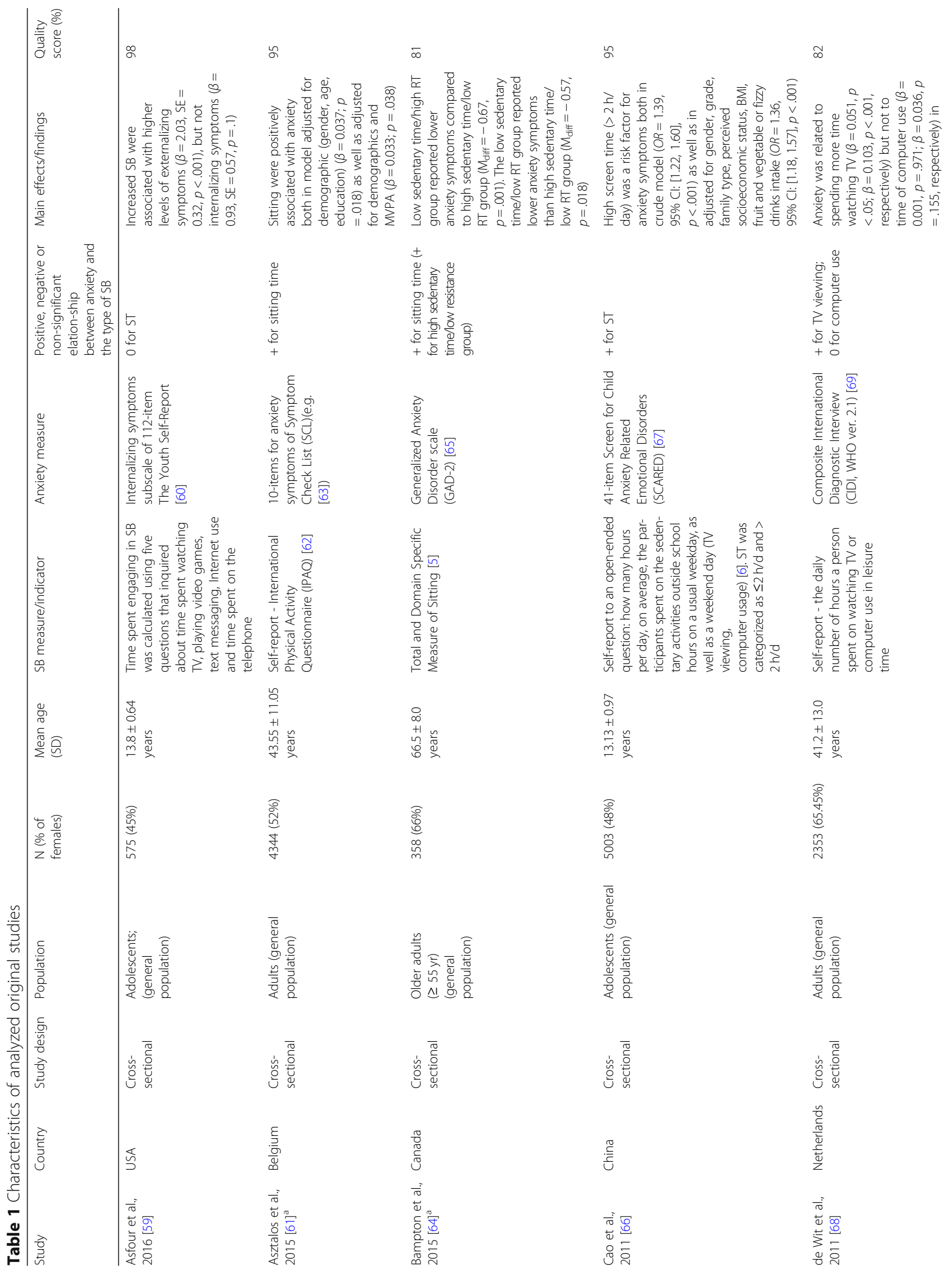




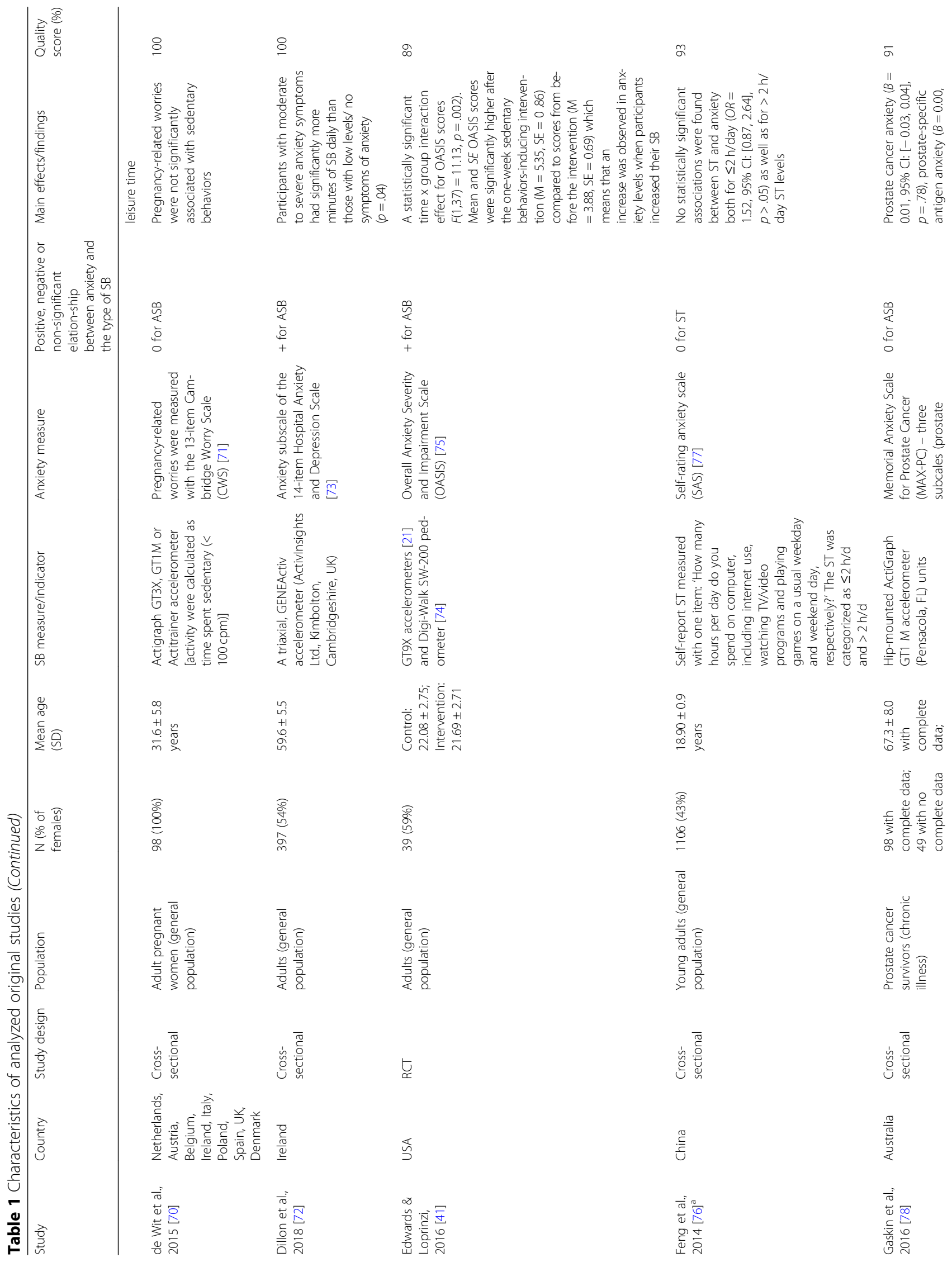




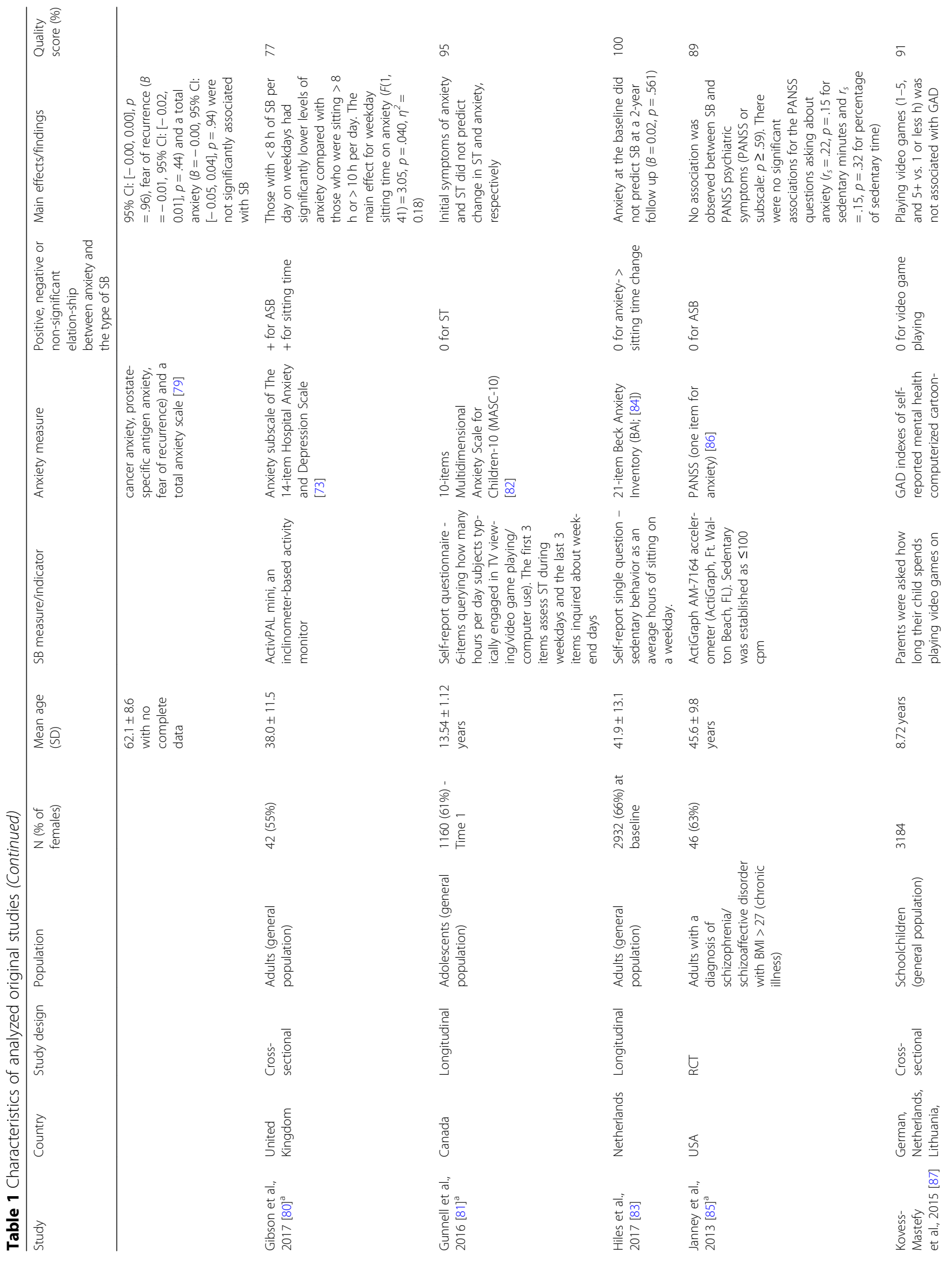




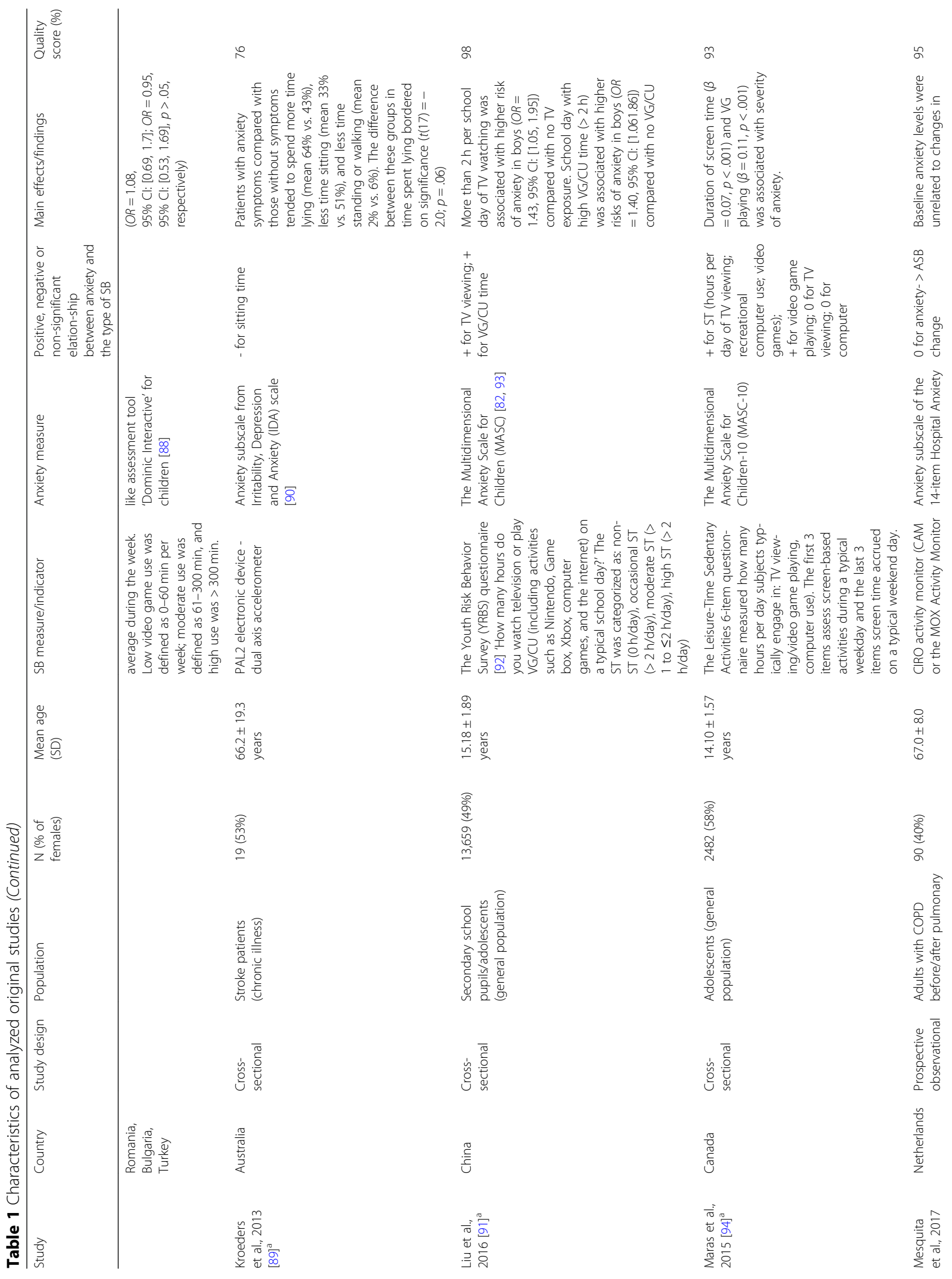




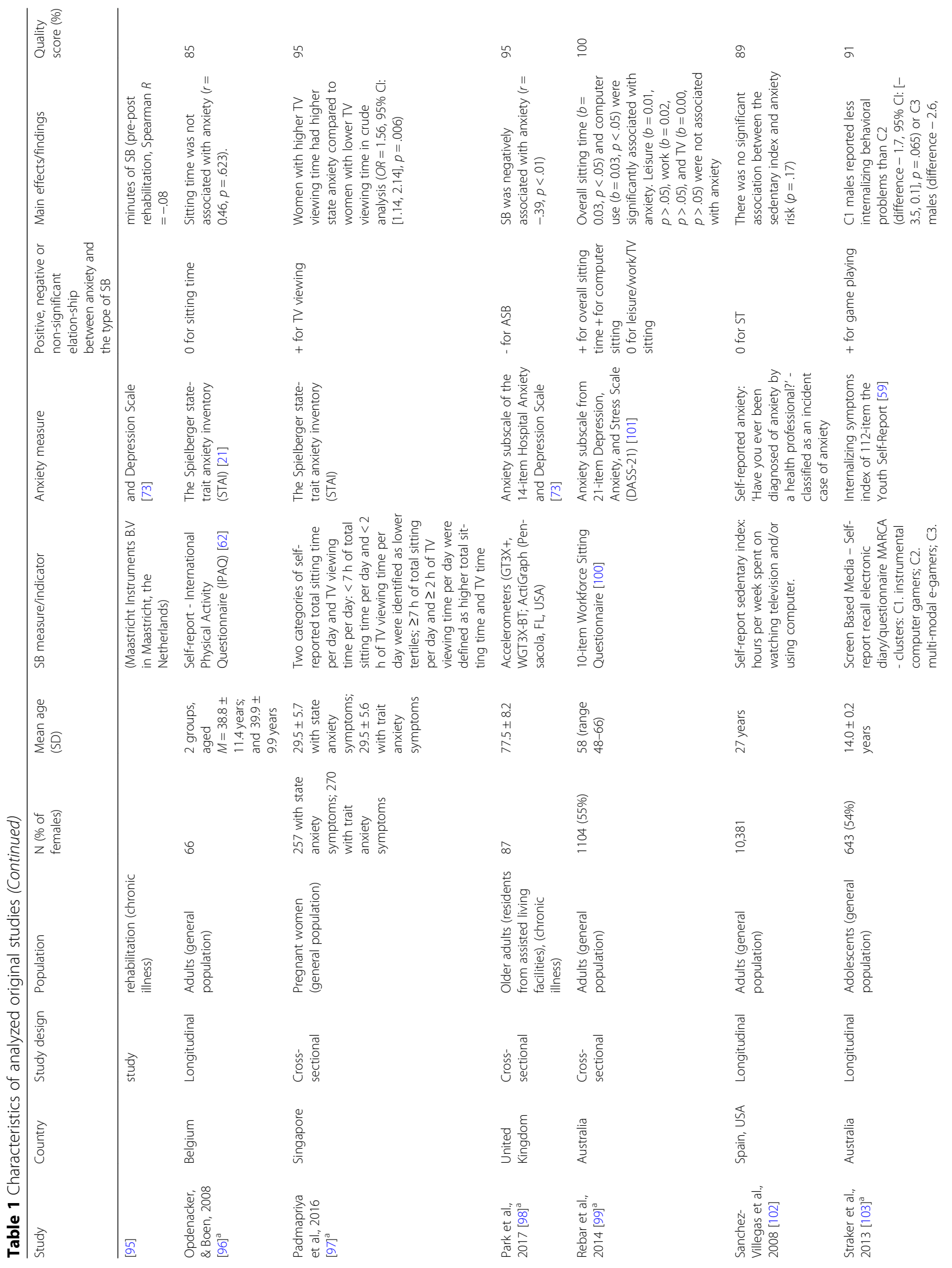




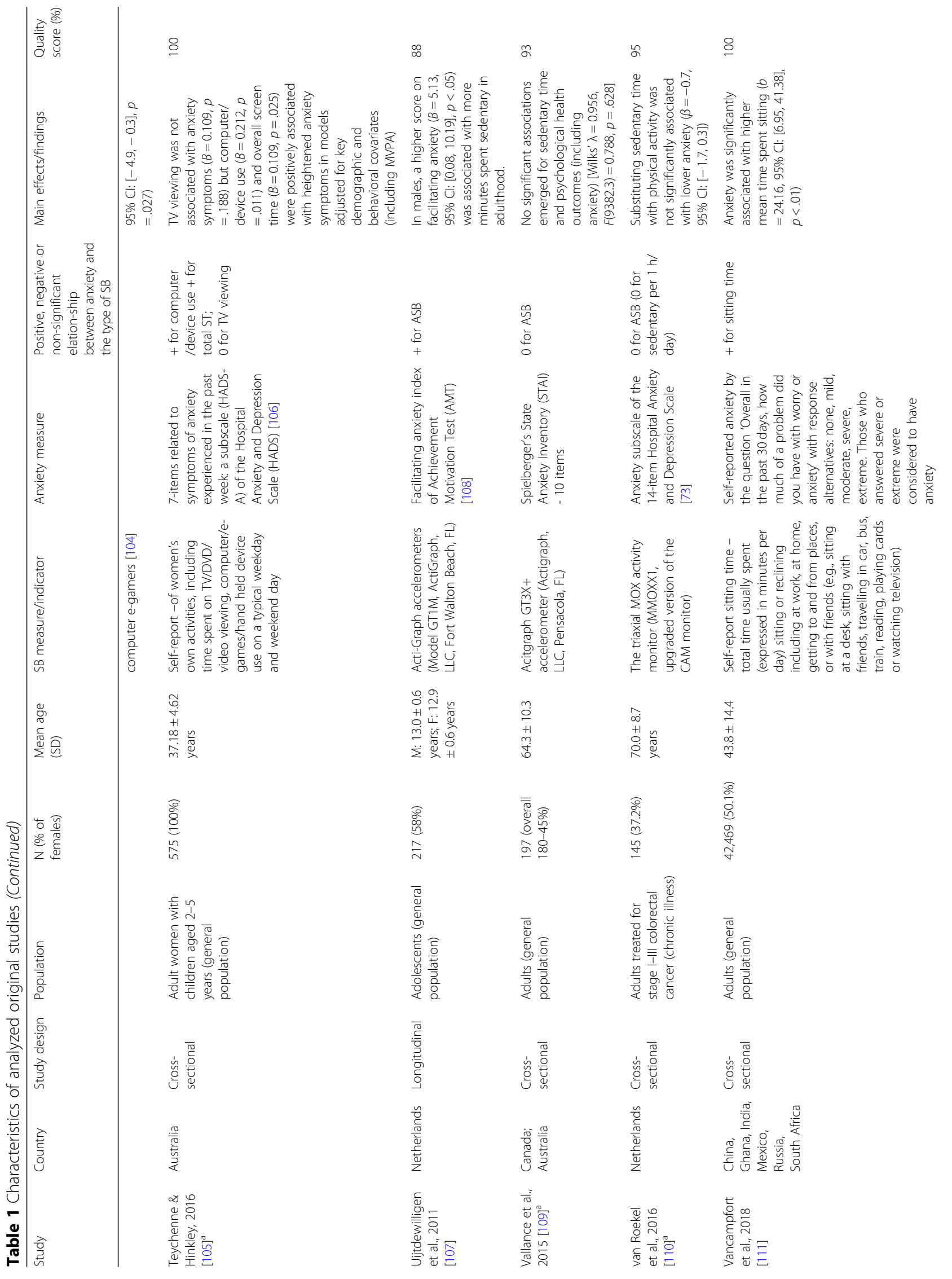




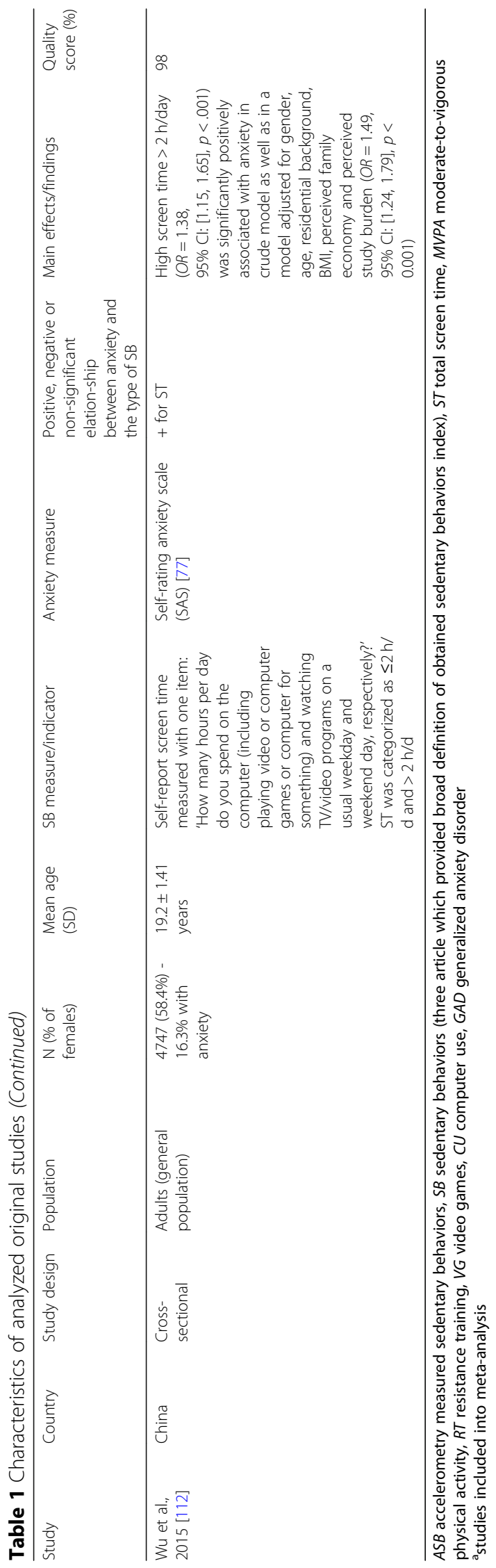


overall score. The cut-point for the inclusion was $65 \%$ (indicating a moderate-to-high quality) of the potential maximum score. The $65 \%$ threshold was chosen from five possible cut-off points $(75,70,65,60$, and $55 \%)$ proposed by Kmet et al. [46], who defined cut-offs as ranging from conservative (75\%) to liberal (55\%), with $65 \%$ representing the moderate cut-off threshold. Overall, the quality of 32 studies was evaluated; one study did not meet the 65\% threshold and was excluded from analyses. Thus, a total of 31 relevant studies met the eligibility criteria and were systematically reviewed. Additionally, 17 out of 31 studies reported coefficients for SB--anxiety associations. These studies were included into the meta-analysis. The concordance coefficients for quality assessment were moderate (all Kappas $\geq .65, p<.001$ ). The overall scores are presented in Table 1 .

\section{Coding}

All stages of data coding were conducted independently by two researchers ( $B S$ and $A B$ ). Next, the third researcher (AL), compared the coding agreed by two researchers ( $\mathrm{BS}$ and $\mathrm{AB}$ ) with the data reported in the original studies. This check was conducted for all included studies (100\%).

For the purpose of this review, SB was defined as any waking behavior characterized by an energy expenditure $\leq 1.5$ METs while in a sitting or reclining posture (Sedentary Behavior Research Network [50]). Where applicable, SB was coded into two broad types proposed by Biddle et al. [7]: (1) total sitting time and (2) total screen time. Additionally, as proposed by the Sedentary Behavior Research Network [8], subtypes of screen-based behaviors were distinguished: (3) TV viewing; (4) any computer use, (5) computer/video/console games playing.

Total sitting time was coded as the amount of time spent sitting/reclining during any leisure activities including sitting at work, reading, TV viewing, sitting at desk, and transport time, etc. Total screen time was coded as the amount of time spent sitting in front of a screen (including TV watching, using mobile devices, internet, computers/game consoles, etc.). For the purpose of the meta-analysis, the following three specific subtypes of screen time were coded: (1) TV viewing, (2) any computer use, (3) computer/video/console games playing (see Additional file 1). A similar approach to SB categorization was used in previous systematic reviews (e.g., [18]) which analyzed total screen time, as well as the subtypes of screen time, such as computer/internet use and TV viewing.

Next, data referring to SB were coded depending on the measurement methods. SB was coded as objectively measured if SB was assessed with accelerometers, pedometers, and position activity electronic loggers (see
Table 1). Self-report measurements of SB included questionnaires and structured interview methods (see Table 1).

Anxiety symptoms were defined as either presence or intensity of symptoms of the most frequent subtypes of anxiety disorders, that is generalized anxiety disorder, phobias, separation anxiety disorder, panic disorder symptoms [22], or other non-clinical anxiety-related reactions (e.g., the level of general anxiety). The applied measures of anxiety symptoms included questionnaires and structured interviews (see Table 1). These measures were used to assess different types of anxiety symptoms such as: phobic anxiety, agoraphobia, panic disorder, generalized anxiety, separation anxiety, social anxiety, facilitating anxiety, debilitating anxiety, trait anxiety, state anxiety, internalizing behavior (anxious-depressed, withdrawn, somatic), prostate cancer anxiety, prostate-specific antigen anxiety, fear of recurrence, or incident cases of anxiety. Several self-report instruments applied in original studies have been established as screening tools with a validated threshold indicating the presence of an anxiety-related diagnosis (e.g., MASC, OASIS, SCARED; see Table 1).

Studies were coded as referring to 'children and adolescents' or 'adults' if the mean age of participants was $<18$ or $\geq 18$ years old, respectively. There were no studies combining children, adolescents, and adult samples.

Next, studies were coded with respect to the health status of participants. The health status was coded as 'general population' if the sample was drawn from a non-clinical, general population and if there were no inclusion criteria regarding the presence of a chronic illness (either physical or mental). Two studies, enrolling samples drawn from a general population of healthy pregnant women, were also coded as 'general population'. The health status was coded as 'with a chronic illness' if the sample was drawn from a population with a diagnosed chronic physical illness (e.g., participants diagnosed with colorectal cancer) or a mental illness (schizophrenia or schizoaffective disorder). There were no studies that examined samples combining 'general population' and 'chronic illness' categories.

\section{Methods of data synthesis and data analysis}

Two methods of data synthesis were applied. The use of two methods of data synthesis allows for a cross-check between meta-analytical findings (obtained with a more robust and established method, but conducted with a smaller number of studies) and a synthesis of data in a systematic review (based on a-priori selected thresholds; not accounting for the heterogeneity of studies).

To synthesize systematic review-allocated data from 31 studies, we applied a synthesis strategy based on a-priori selected thresholds, accounting for the proportion of significant associations across included studies (for previous use of this strategy see Boberska et al. [51]; 
Luszczynska et al. [52]). Data indicating that the association between an index of SB and an index of anxiety symptoms was significant were retrieved from the original research and defined as 'a relationship unit'. Subsequently, depending on the direction of the association each unit was coded as ' + ' or '-' if a significant positive association between SB and anxiety was reported, and ' 0 ' if the association was not significant. To summarize findings of the original studies, evidence ratings were coded as: (1) 'showing corroborating evidence' if $60-100 \%$ of the original studies supported the association; or (2) 'showing preliminary support' if $50-59 \%$ of the studies supported the association [53].

The indicators of the associations between SB and anxiety symptoms were retrieved (in particular, the correlation coefficients, regression coefficients, path coefficients, odds ratios etc.). In case of experimental studies, the coefficient representing the main effect of a manipulation was used in the data analysis. In case of studies comparing groups with different levels of SB, data regarding levels of anxiety symptoms in each group were obtained and compared. In case of longitudinal studies, coefficients representing the associations between the baseline and the latest available follow-up were included into analysis.

Overall, 25 studies yielded 1 association coefficient each, 3 studies yielded 2 coefficients, 2 studies yielded 3 coefficients, and 1 study yielded 4 coefficients. Two or more coefficients were obtained if the original study provided indicators of associations for more than one type of SB (e.g., 1 coefficient for total sitting time and 1 for TV watching). Thus, a total of 41 coefficients from 31 studies were included into the data synthesis.

In order to calculate the estimates of the average effects, heterogeneity, and the effects of the moderators, data obtained from 17 original studies were meta-analyzed using the Comprehensive Meta-Analysis software (version 2.2) [54], which is the most extensively used meta-analytic software [55]. The meta-analysis was conducted for original research providing bivariate association coefficients obtained in an equation without covariates. Pearson's correlation was used as the effect size indicator (see Additional file 1). Correlations were synthesized to form the cumulative effect size by transforming into Fisher's $z$ according to the procedures described by Borenstein et al. [56]. If a publication did not provide the respective coefficients, the authors were contacted by e-mail with a query to provide $r$ coefficients. Seven correlation coefficients were obtained from original publications; 10 correlation coefficients were obtained from authors directly.

A random-effects model was used to calculate the estimate of the population effect size. To investigate the asymmetry which may be caused by publication bias, the funnel plot for 17 studies (see Fig. 2) was screened and Egger's test was conducted. Statistical analyses followed the procedure described by Hunter and Schmidt [57]. First, an overall effect was determined for all original studies included in the meta-analysis. Next, we performed moderation analyses to investigate if there were differences in estimated effects depending on participants' age, health status, and the type of sedentary behavior. The moderation analyses were conducted if the number of respective subgroups was $k \geq 2$. Only one study included self-reports of children, therefore research enrolling children and adolescents were combined into one subgroup.

To test the effects of the moderators, the estimate of the effect size was calculated for each level of a moderator. Next, group mean effect sizes were compared using the $Q$ B statistic. Qв is used as an omnibus test for detecting between-group differences [58]. A significant Qв value indicates that estimates of the average effect differ significantly for $\geq 2$ levels of the moderator.

\section{Results \\ Search results}

We identified a total of $k=31$ studies eligible for inclusion into a systematic review and 17 studies eligible for inclusion in the meta-analysis. Details of the search process are presented in Fig. 1. Data retrieved from the original studies are summarized in Table 1.

\section{A synthesis of findings from studies included into the systematic review}

A total of 99,192 participants were enrolled in all 31 studies with sample sizes ranging from 19 to 42,469 participants. Participants' age ranged from 6 to 70+. Six studies (20\%) included adolescents, 1 (3\%) included children and adolescents, and 1 (3\%) enrolled children only. Twenty-three studies (74\%) were conducted in adult populations. Overall, 25 studies (81\%) involved general population samples, whereas 6 (19\%) enrolled adults with a chronic mental illness (i.e., schizophrenia or schizoaffective disorder) or physical illness (stroke, colorectal cancer, chronic obstructive pulmonary disease, cardiovascular diseases, musculoskeletal diseases, diabetes, lung disease, obesity, prostate cancer survivors). Across original studies, the majority $(k=22,71 \%)$ applied cross-sectional designs, 7 (23\%) were of correlational longitudinal designs, 2 (6\%) studies were experimental. Regarding the assessment of $\mathrm{SB}$, the majority of studies $(k=19,61 \%)$, relied on self-report whereas $k=12$ (39\%) studies used objective methods. Assessments of anxiety symptoms were mostly self-report $(k=29 ; 94 \%)$ whereas in $k=2(6 \%)$ studies anxiety symptoms were assessed with an interview. Original studies were conducted in 24 different countries, across Europe, North America, Asia, Australia, and Africa. The quality score assessment of included studies ranged between 76 and $100 \%$ (see Table 1). 
Across 41 associations obtained from original studies, 21 (51\%) indicated that higher levels of SB were associated with higher levels of anxiety (Table 2). Fifty-eight percent (7 out of 12) of obtained associations among children/adolescent samples indicated corroborating evidence for a positive link between SB and anxiety. For adults, 61\% (14 out of 23) of associations were positive. Evidence supporting the SB--anxiety relationship among adults from the general population was indicated by 14 (48\%) out of 29 coefficients reported in original studies. There was no support for the SB-anxiety symptoms association in studies enrolling adults with chronic illnesses ( 0 out of 6 obtained associations). No extracted study with children/adolescents was conducted among participants with a chronic illness.

Additional analyses focused on the type of SB (total sitting time vs. screen time) and the subtypes of screen time (TV viewing vs. computer use/internet use/video game playing) and its measurement (objective vs. self-report) (Table 2). Corroborating evidence for a positive association between $\mathrm{SB}$ and anxiety symptoms was found for: self-reported sitting time (6 out of 9 original studies accounting for this index; $67 \%)$; computer use/internet use/video game playing (5 out of 8 studies; 63\%). However, only 3 out of 6 original studies (50\%) and 4 out of 8 studies (50\%) indicated a positive relationship between TV viewing and anxiety and total screen time and anxiety, respectively. Finally, across studies focusing on objectively measured total sitting time and anxiety, only 4 out of $11(36 \%)$ yielded positive associations suggesting that higher levels of SB were related to higher levels of anxiety symptoms.

\section{The meta-analytic synthesis of findings}

A total of 27,443 participants were enrolled in 17 original studies (see Table 3), with sample sizes ranging from 19 to $13,659(M=1614)$ participants, and $64.18 \%$ women participating. One study did not provide the distribution for gender. Mean age of the participants was 41.91 years old $(S D=22.05)$, ranging from 13.54 to 77.5 . Five studies were conducted among children/adolescents from the general population $(N=19,050$, mean age $=15.34, S D=2.62)$. Seven studies enrolled adults $(N=7125$, mean age $=51.44$, $S D=16.03$ ) without any clinical illness reported (two studies enrolled pregnant women). Five studies enrolled adults with a chronic physical or mental illness (participants: $N=475$, mean age $=64.72, S D=11.82$ ), such as cardiovascular diseases, musculoskeletal diseases, diabetes, lung disease, obesity, schizophrenia or schizoaffective disorders, stroke, colon or colorectal cancer. Thirteen studies (76\%) had a cross-sectional design, 3 (18\%) used a longitudinal correlational design, and 1 (6\%) applied an experimental longitudinal design.

An inspection of the funnel plot and the values of the Egger test (intercept: $2.11 ; p<0.01$ ) indicated that the smaller studies tended to have better test performance. These findings suggest a likelihood of a publication bias.

Table 3 displays the results of the meta-analysis, including the estimates of the average effects and moderator analyses. The estimate of the overall average effect for the association between indicators of SB and anxiety symptoms was significant and small with weighted $r=.093,95 \%$ CI $[.055, .130], p<.001$, suggesting that higher levels of SB are associated with higher levels of anxiety symptoms. Table 3 displays the estimates of heterogeneity, $\mathrm{Tau}^{2}$, Tau, and $I^{2}$ [113]. To demonstrate how much an effect might vary across different

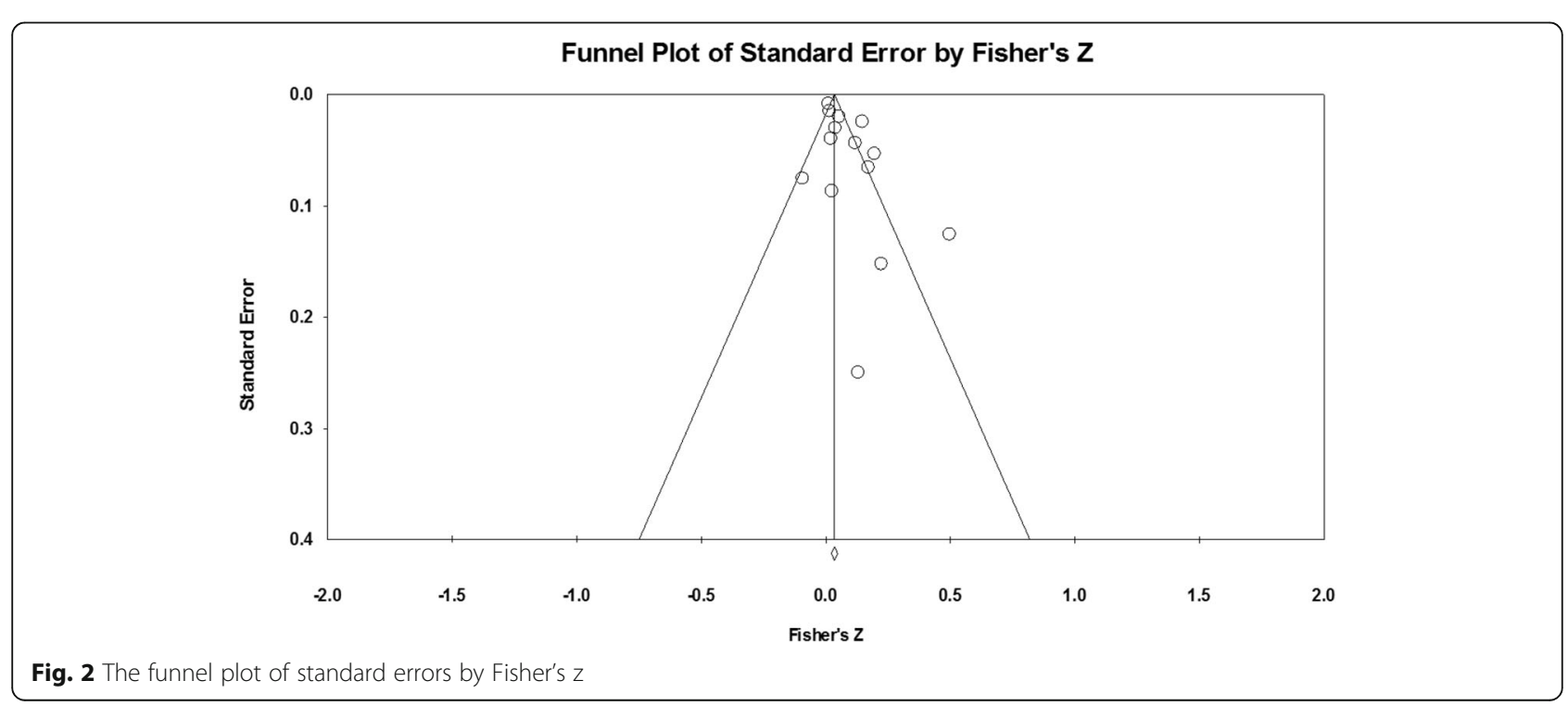


populations, prediction intervals were calculated with Tau ( $\tau=.058$ ), using an approach described by Borenstein et al. [114]. Based on these findings, it can be expected that in $95 \%$ of different populations, the true correlation will fall in the approximate range of -.030 to .214 .

Moderation analyses were performed to address this dispersion and to take into account the estimates of obtained heterogeneity. First, we tested if age group (children/adolescents vs. adults) would moderate the association between SB and anxiety (Table 3). Two types of studies were compared: (1) enrolling children/adolescents $(k=5$ samples) and (2) enrolling adults aged over 18 years $(k=7)$. As there were no studies with children/adolescents with a chronic illness, studies conducted among adults with chronic illnesses $(k=6)$ were excluded from the analysis to avoid the effect of a potentially confounding factor, the presence of a chronic illness. The comparison yielded a statistical trend for a difference between obtained estimates $(p=.085)$, indicating that the associations tended to be stronger in adults, compared to associations obtained for children/adolescents. To test the moderating effect of health status (adults from the general population vs. adults with a chronic mental of physical illness) two types of studies were compared: (1) enrolling adults from the general population $(k=5)$; and (2) enrolling adults with a chronic mental or physical illness $(k=6)$. Results indicated no differences between the average effects obtained for the two groups $(p=.820)$.

The moderating effect of the type of SB was investigated with a comparison of two subgroups: (1) studies which investigated total screen time $(k=6)$, and (2) studies which investigated total sitting time $(k=5)$. Only studies that used self-report measures were included into this moderation analysis (total $k=11$ ). Results did not show any significant differences between the estimates of average effects obtained for the two types of SB $(p=.137)$.

Next, we conducted the moderation analysis comparing associations between anxiety symptoms and three subtypes of screen time (TV viewing vs. computer using vs. computer/video/console games playing). This analysis was performed with data obtained from 4 studies, all of which accounted for $\geq 2$ types of SB (e.g., TV viewing and computer using separately). In particular, 8 coefficients were included: 4 coefficients were obtained for TV viewing, 2 for computer using, and 3 for computer/ video/console games playing. Thus, we compared associations obtained for: (1) indicators of time spent watching TV $(k=3),(2)$ indicators of time spent using a computer $(k=2)$, and (3) indicators of time spent on playing computer/video games $(k=2)$. The comparison of all three types of SB yielded a statistical trend for a difference ( $p$ $=.080$ ). The following two-group comparisons indicated that the average effects for computer/video/console games playing were significantly smaller than the effects for computer using $(p<.001)$. There were no significant differences in the effects of TV viewing compared to computer/video/console games playing $(p=.475)$ and TV viewing compared to computer use $(p=.166)$.

Finally, we tested the moderating effects of the type of measurement of SB (self-report, $k=11$ vs. objective measurement with accelerometry, $k=6$ ). Only correlation coefficients for total SB time were used in this moderation analysis. This strategy was chosen to avoid confounding results with the effects of the type of SB. Results of the moderation analysis yielded a non-significant difference ( $p=.299)$ between estimates obtained for the two types of SB measurement.

Although four original studies employed a longitudinal design, we did not conduct a moderation analysis to test differences between cross-sectional vs. time-lagged effects. Such an analysis was impossible because only one longitudinal study provided time-lagged coefficients.

\section{Discussion}

This study provides a preliminary synthesis and metaanalysis of evidence for associations between SB and anxiety symptoms. Results of the meta-analysis indicated that higher levels of SB were related to higher levels of anxiety symptoms, yet the estimate of the average effect was weak (weighted $r=.093$ ). The conclusions obtained from this meta-analysis are preliminary due to a relatively small number of studies included, their heterogeneity, and the inclusion of studies with cross-sectional designs. The systematic review indicated preliminary support for a significant association between SB and anxiety symptoms, with $51 \%$ of significant and positive associations (42.5\% of non-significant associations, 6.5\% of significant and negative associations). This moderate evidence, obtained in the synthesis of 31 studies is in line with findings of a previous review [31], presenting evidence obtained in 9 original studies.

A relatively small percentage (51\%) of significant, positive associations between SB and anxiety symptoms was identified in the systematic review. This fact may be due to the methodology of the original studies. The majority of studies yielding non-significant associations were conducted with relatively small samples (with $N<100$ ). Our meta-analysis shows that the average effect may also be small. Thus, the studies with small samples were probably underpowered to detect the associations between SB and anxiety symptoms. Future research targeting SB-anxiety associations should assume small effect sizes for a-priori power analyses.

The weakness of the overall association between SB and anxiety symptoms may have several causes. The association between SB and anxiety symptoms may be of indirect rather than direct nature, with a number of involved 


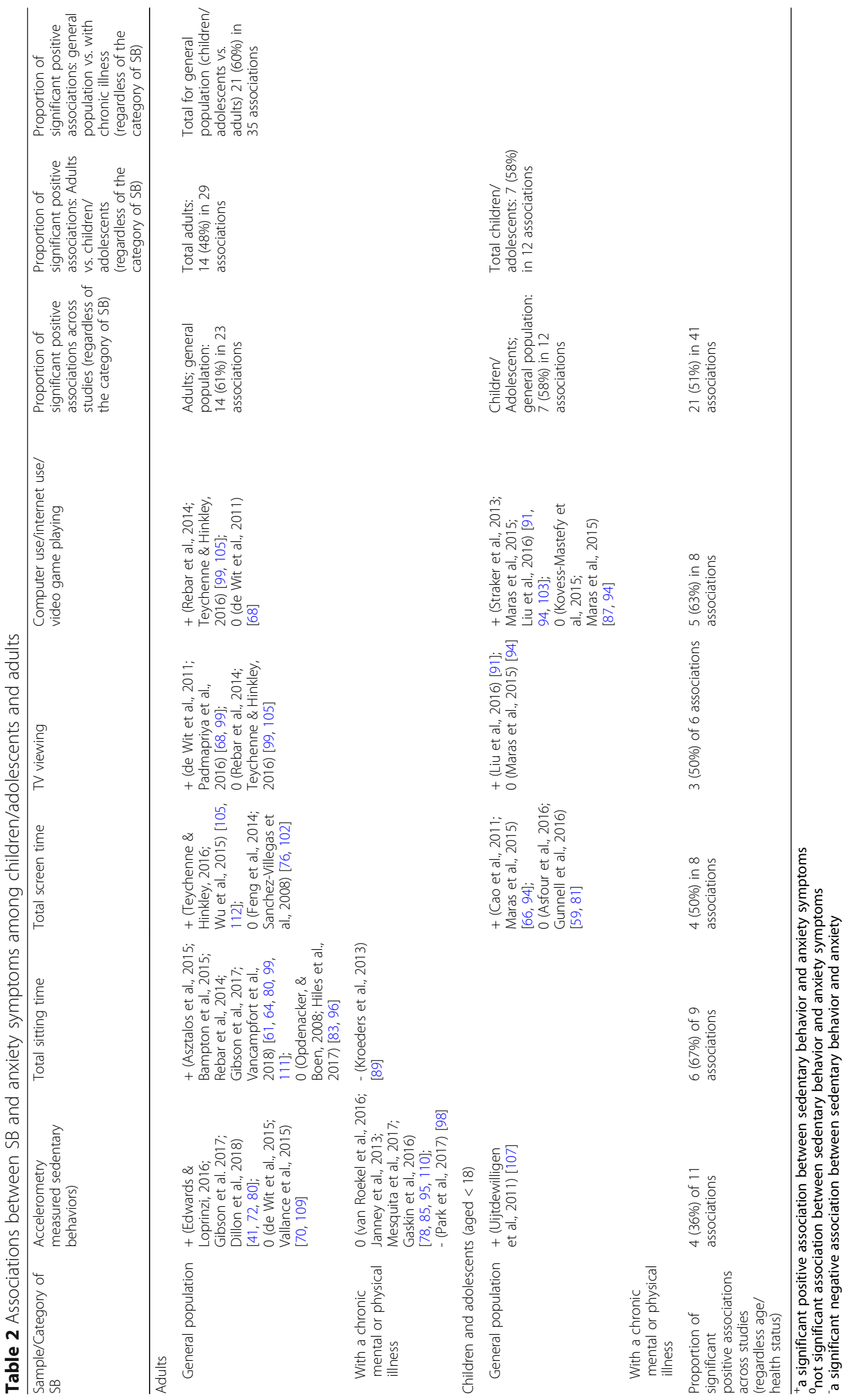


Table 3 Results of meta-analysis and moderation analysis of the association between SB and anxiety symptoms

\begin{tabular}{|c|c|c|c|c|c|c|c|c|c|c|c|}
\hline & \multirow[t]{2}{*}{$\begin{array}{l}\text { Estimate of the } \\
\text { average effect }\end{array}$} & \multirow[t]{2}{*}{$\begin{array}{l}\text { Range of correlation } \\
\text { coefficients retrieved } \\
\text { from original studies }\end{array}$} & \multirow[t]{2}{*}{$\begin{array}{l}95 \% \mathrm{Cl} \text { for the } \\
\text { estimate of the } \\
\text { average effect }\end{array}$} & \multirow[t]{2}{*}{ N } & \multirow[t]{2}{*}{ K } & \multicolumn{4}{|c|}{ Heterogeneity } & \multicolumn{2}{|c|}{$\begin{array}{l}\text { Test for } \\
\text { moderating } \\
\text { effects }\end{array}$} \\
\hline & & & & & & Q & $P^{2} \%$ & Tau & $\mathrm{Tau}^{2}$ & $\overline{Q_{B}}$ & $P$ \\
\hline Overall effect & .093 & $.01 ; .46$ & {$[.05 ; .13]$} & $26,204^{b}$ & 17 & $\begin{array}{l}77.04 \\
p<.001\end{array}$ & 79.23 & .06 & .003 & & \\
\hline \multicolumn{12}{|c|}{ Moderators effects for overall effect and levels of respective moderators } \\
\hline Age group & & & & & & & & & & 2.97 & .085 \\
\hline Children/adolescents & .05 & $.01 ; .17$ & {$[-.01 ; .11]$} & 17,873 & 5 & & & & & & \\
\hline Adults (over 18) & .12 & $.02 ; .46$ & {$[.06 ; .17]$} & 7868 & 7 & & & & & & \\
\hline Health status & & & & & & & & & & 0.05 & .820 \\
\hline $\begin{array}{l}\text { Adults with a chronic physical or } \\
\text { mental illness }\end{array}$ & .16 & $.03 ; .39$ & {$[.03 ; .30]$} & 463 & 5 & & & & & & \\
\hline Adults from the general population & .15 & $.02 ; .46$ & {$[.05 ; .23]$} & 6990 & 6 & & & & & & \\
\hline \multicolumn{6}{|c|}{ The type of measurement of sedentary behaviors } & & & & & 1.08 & .299 \\
\hline Objective & .14 & $.03 ; .39$ & {$[.04 ; .24]$} & 505 & 6 & & & & & & \\
\hline Self-report & .08 & $.01 ; .46$ & {$[.04 ; .12]$} & 25,699 & 11 & & & & & & \\
\hline The type of SB & & & & & & & & & & 2.21 & .137 \\
\hline Total sitting time & .12 & $.02 ; .46$ & {$[.06 ; .19]$} & 7298 & 5 & & & & & & \\
\hline Total screen time & .06 & $.01 ; .17$ & {$[.00 ; 11]$} & 18,401 & 6 & & & & & & \\
\hline \multicolumn{6}{|c|}{ The sub-type of screen use-related behaviors } & & & & & $5.04^{\mathrm{a}}$ & .080 \\
\hline Computer using & .12 & $.10 ; .14$ & {$[.05 ; .18]$} & 2183 & 2 & & & & & & \\
\hline Computer/video games playing & .02 & $.02 ; .03$ & {$[-.03 ; .08]$} & 15,896 & 2 & & & & & & \\
\hline TV viewing & .05 & $-.001 ; .10$ & {$[.01 ; .09]$} & 16,475 & 4 & & & & & & \\
\hline
\end{tabular}

Note. $^{\text {a }}$ - Two-group comparisons revealed that effect sizes marked with bold were significantly different

b - data from 26,204 participants were included from the total of 27,443 who were enrolled across 17 studies. The difference between the number of participants in analyses vs. the original study samples occurred as in cases the coefficients provided by authors in response to our inquiry were based on a smaller $N$ than $N$ reported in the publication

psychosocial and physiological mediating mechanisms. For example, in line with the displacement hypothesis [33, 34], it may be expected that a withdrawal form anxiety-reducing activities (such as physical activity, active social face-to-face interactions) is followed by SB. Therefore, SB that may constitute an avoidance behavior, exacerbating avoidance-related thoughts, that result in anxiety. Furthermore, a withdrawal from anxiety-reducing activities and subsequent SB engagement may result in lower self-esteem, which, in turn, may prompt anxiety symptoms (for the role of self-esteem see Smith et al. [35]). Future research should look more carefully into the underlying mediating mechanisms, instead of focusing solely on direct associations between SB and anxiety.

Another cause of weak associations between SB and anxiety may lie in the different operationalizations and different instruments used to assess SB and anxiety in the original studies. SB and anxiety were defined, operationalized, and measured in multiple ways, which poses a major challenge to comparability. Analyzed studies usually relied on a global index of SB, namely total SB time. Although this index is recommended, recent evidence suggests that physiological effects of SB may be better captured with other indicators, e.g. time composition (i.e., the relative proportion of total SB time, light-intensity physical activity, and moderate-to-vigorous-intensity physical activity [39]). Such indices would also allow for a more thorough validation of the displacement hypothesis, accounting for other energy expenditure behaviors. Moreover, due to the heterogeneity of operationalizations and measurement of anxiety symptoms we were unable to clarify to what degree the definitions and assessments of anxiety applied in original trials may have contributed to the overall heterogeneity of the estimates of the average effect.

Although the association between SB and anxiety symptoms was weak, its significance should be highlighted. Previous meta-analyses investigating the associations between SB and global indicators of mental health (i.e. emotional quality of life) showed a non-significant association [51]. Significant associations observed in this systematic review and meta-analysis suggest that SB may form links with specific aspects of mental health, such as anxiety symptoms. Further research should investigate if the strength of $\mathrm{SB}-$ mental health outcome depends on the type of the 
mental health outcome, that is anxiety, mood, somatoform, or sleep disorders.

We observed some differences between meta-analytic and systematic review findings. For example, the effect of age on the SB-anxiety symptoms relationship was supported by the systematic review, with significant associations emerging in $58 \%$ of associations tested among children and $48 \%$ of associations tested among adults. In turn, this meta-analysis indicated a trend for more consistent, significant associations among adults, compared to weaker associations among children/adolescents ( $p$ $=.085)$. These discrepancies may be explained by our meta-analytic strategy which excluded studies with adults with a chronic mental or physical illness, as we identified no study with children/adolescents with a chronic illness. The moderating effects of age may further depend on the health status of the studied population. Future research should carefully investigate synergistic effects of age and health status.

The present study provides a preliminary synthesis of evidence which may inform clinical practice. Obtained findings, indicating that the observed effects are similar across groups differing in age and health, implicate the breadth of the target population for health promotion programs. Broad target populations may be a vector of successful implementation of health promotion programs [115].

A limitation of the present work refers to its inability to clarify the order in which SB and anxiety symptoms operate. Although theoretical models of stress resilience as well as displacement hypotheses [30,33] suggest that SB precede and explain anxiety, it may be also assumed that anxiety may lead to a withdrawal from activities such as face-to-face social interactions, and thus allow for more time spent in SB. Our findings do not allow for any conclusions regarding the order of variables in this relationship, because the majority of included original studies had cross-sectional designs. Moreover, due to a limited number of studies focusing on children only or older adults only, we were unable to conduct a systematic investigation of age-related differences in the associations of SB and anxiety across the lifespan. The comparisons were made for broader age groups (children/adolescents vs. adults/ older people), therefore the conclusions referring to the effects of age should be considered as preliminary. Furthermore, analyses of the moderating role of age rely on a comparison of effects obtained in independent and heterogeneous cohorts. More research using longitudinal designs that would allow to establish the strengths of SB-anxiety associations across the life-span would provide more conclusive evidence for the existence of a moderating effect of age.

There are several other reasons for considering the present findings as preliminary. First, a small number of studies were entered into the meta-analysis. Second, the studied populations and indicators of SB and anxiety were of high heterogeneity. In particular, the results of the moderator analyses should be treated with caution as they were conducted with a small number of original studies which limits the likelihood of obtaining statistically significant findings. For example, the comparisons of subtypes of screen-related behaviors (computer use vs. playing with video/console games) were based on meta-analysis of 4 coefficients only, therefore any conclusions regarding the effect of the subtypes of screen-related behaviors are preliminary. Also, future studies should use more precise methods of assessing the content of screen time activities (e.g., using one's mobile to play a game vs. social media use). Precise assessment would allow for a better identification of the subtypes of SB. The limited number of studies did not allow for a thorough test of combined moderating effects of age and health status. Other potential sociodemographic moderators, such as gender, were not analyzed because the original studies did not provide data allowing for the calculation of SB--anxiety association coefficients for men and women separately. The categorization regarding health status was suboptimal, as the two distinguished categories were very broad and comprised subcategories. In particular, the 'chronic illness' category referred to physical and mental health issues, whereas the 'general population' category included studies focusing on subsamples of general population (i.e., healthy pregnant women). Unfortunately, the number of studies was too small to conduct further moderator analyses (e.g. mental vs physical chronic illness). Consequently, the effects of health status should be further investigated before any generalizations are made. The use of self-reports to measure SB and anxiety symptoms may inflate the relationship between these two constructs. The value of the Egger test indicated a likelihood of publication bias, however, such values are typical for meta-analyses conducted with a limited number of studies $[51,116]$.

\section{Conclusions}

Despite its limitations, this study provides a novel insight into the associations between SB and anxiety symptoms. The meta-analytic findings, based on 17 original studies enrolling children/adolescents and adults from the general population or with a chronic mental or physical illness, suggested that higher levels of SB are associated with higher levels of anxiety symptoms (the estimate of the overall average effect: $r=.093$ ). The associations remain largely similar, regardless of age, health status, SB operationalization and measurement. Trends for stronger SB-anxiety associations among adults (compared to children/adolescents) should be investigated further. 


\section{Additional file}

Additional file 1: Summary of studies included in the meta-analysis. Table displays $r$ coefficients used in meta-analysis and coding for respective moderators. (DOCX 73 kb)

\section{Abbreviations}

ASB: Accelerometry measured sedentary behaviors; Cl: Chronic illness; CU: Computer use; GAD: Generalized anxiety disorder; MVPA: Moderate-tovigorous physical activity; RT: Resistance training; SB: Sedentary behaviors; ST: Screen time; STAI: The Spielberger's state-trait anxiety inventory; TV: Television; VG: Video games

\section{Acknowledgements}

Not applicable

\section{Funding}

The study was funded by the National Science Centre, Poland, grant no. 2017/27/B/HS6/00092, awarded to Aleksandra Luszczynska. The funding institution had no role in the study design, collection, analysis or interpretation of the data, writing the manuscript, or the decision to submit the paper for publication.

\section{Availability of data and materials}

All data generated or analyzed during this study are included in this published article [and its supplementary information files].

\section{Authors' contributions}

$B S, A B, A L$ designed the study, performed literature searches, extracted data, performed quality assessment and statistical analysis and took the lead in manuscript writing. $\mathrm{BS}$ and $\mathrm{AB}$ contributed equally to this work and share the first authorship jointly. NK, DHH, JK, JR contributed to the study conception and manuscript writing. All authors have approved the final manuscript.

\section{Ethics approval and consent to participate}

Not applicable

\section{Consent for publication}

Not applicable

\section{Competing interests}

The authors declare that they have no competing interests.

\section{Publisher's Note}

Springer Nature remains neutral with regard to jurisdictional claims in published maps and institutional affiliations.

\section{Author details}

${ }^{1}$ Department of Nervous System Diseases, Wroclaw Medical University, Bartla 5 Street, 51-618 Wroclaw, Poland. ${ }^{2}$ Wroclaw Faculty of Psychology, SWPS University of Social Sciences and Humanities, Ostrowskiego 30b Street, 53-238 Wroclaw, Poland. ${ }^{3}$ Department of Education and Psychology, Freie Universität Berlin, Habelschwerdter Allee 45, 14195 Berlin, Germany. ${ }^{4}$ Trauma, Health, \& Hazards Center, University of Colorado, 1420 Austin Bluffs Pkwy, Colorado Springs, CO 80918, USA.

Received: 20 July 2018 Accepted: 27 March 2019

Published online: 30 April 2019

\section{References}

* indicates studies included in the meta-analysis

1. Tremblay MS, Colley RC, Saunders TJ, Healy GN, Owen N. Physiological and health implications of a sedentary lifestyle. Appl Physiol Nutr Metab. 2010; 35(6):725-40. https://doi.org/10.1139/h10-079.

2. Owen N, Healy GN, Matthews CE, Dunstan DW. Too much sitting: the population health science of sedentary behavior. Exerc Sport Sci Rev. 2010; 38(3):105-13. https://doi.org/10.1097/jes.0b013e3181e373a2.
3. Pate RR, O'Neill JR, Lobelo F. The evolving definition of "sedentary". Exerc Sport Sci Rev. 2008;36(4):173-8. https://doi.org/10.1097/jes. 0b013e3181e373a2.

4. Kelly LA, McMillan DG, Anderson A, Fippinger M, Fillerup G, Rider J. Validity of actigraphs uniaxial and triaxial accelerometers for assessment of physical activity in adults in laboratory conditions. BMC Med Phys. 2013;13(1):5. https://doi.org/10.1186/1756-6649-13-5.

5. Marshall S, Kerr J, Carlson J, Cadmus-Bertram L, Patterson R, Wasilenko K, Crist K, Rosenberg D, Natarajan L. Patterns of weekday and weekend sedentary behavior among older adults. J Aging Phys Act. 2014;23(4):53441. https://doi.org/10.1123/japa.2013-0208.

6. Schmitz KH, Harnack L, Fulton JE, Jacobs DR Jr, Gao S, Lytle LA, Van Coevering P. Reliability and validity of a brief questionnaire to assess television viewing and computer use by middle school children. J Sch Health. 2004;74(9):370-7. https://doi.org/10.1111/j.1746-1561.2004.tb06632.x.

7. Biddle SJ, García Bengoechea E, Wiesner G. Sedentary behaviour and adiposity in youth: a systematic review of reviews and analysis of causality. Int J Behav Nutr Phys Act. 2017;14(1):43. https://doi.org/10.1186/s12966-017-0497-8.

8. Tremblay MS, Aubert S, Barnes JD, Saunders TJ, Carson V, Latimer-Cheung AE, Chastin SFM, Altenburg TM, Chinapaw MJM. SBRN Terminology Consensus Project Participants. Sedentary Behavior Research Network (SBRN) - Terminology Consensus Project process and outcome. Int J Behav Nutr Phys Act. 2017;14(1):75. https://doi.org/10.1186/s12966-017-0525-8.

9. Arundell L, Fletcher E, Salmon J, Veitch J, Hinkley T. A systematic review of the prevalence of sedentary behavior during the after-school period among children aged 5-18 years. Int J Behav Nutr Phys Act. 2016;13:93. https://doi. org/10.1186/s12966-016-0419-1.

10. Harvey JA, Chastin SF, Skelton DA. Prevalence of sedentary behavior in older adults: a systematic review. Int J Environ Res Public Health. 2013;10(12): 6645-61. https://doi.org/10.3390/ijerph10126645.

11. Dunstan DW, Barr EL, Healy GN, Salmon J, Shaw JE, Balkau B, Magliano DJ Cameron AJ, Zimmet PZ, Owen N. Television viewing time and mortality: the Australian diabetes, obesity and lifestyle study (AusDiab). Circulation. 2010:121(3):384-91. https://doi.org/10.1161/circulationaha.109.894824.

12. Katzmarzyk PT, Church TS, Craig CL, Bouchard C. Sitting time and mortality from all causes, cardiovascular disease, and cancer. Med Sci Sports Exerc. 2009;41(5):998-1005. https://doi.org/10.1249/mss.0b013e3181930355.

13. Thorp AA, Owen N, Neuhaus M, Dunstan DW. Sedentary behaviors and subsequent health outcomes in adults a systematic review of longitudinal studies, 1996-2011. Am J Prev Med. 2011:41(2):207-15. https://doi.org/10. 1016/j.amepre.2011.05.004

14. de Rezende LF, Rodrigues Lopes M, Rey-López JP, Matsudo VK, Luiz OC. Sedentary behavior and health outcomes: an overview of systematic reviews. PLoS One. 2014;9(8):e105620. https://doi.org/10.1371/journal.pone.0105620.

15. Teychenne M, Ball K, Salmon J. Sedentary behavior and depression among adults: a review. Int J Behav Med. 2010;17(4):246-54. https://doi.org/10.1007/ s12529-010-9075-z.

16. Allen MS, Walter EE, Swann C. Sedentary behaviour and risk of anxiety: a systematic review and meta-analysis. J Affect Disord. 2019;242:5-13. https:// doi.org/10.1016/j.jad.2018.08.081.

17. Hoare E, Milton K, Foster C, Allender S. The associations between sedentary behaviour and mental health among adolescents: a systematic review. Int J Behav Nutr Phys Act. 2016;13(1):108. https://doi.org/10.1186/s12966-016-0432-4.

18. Teychenne M, Costigan SA, Parker K. The association between sedentary behaviour and risk of anxiety: a systematic review. BMC Public Health. 2015; 15:513. https://doi.org/10.1186/s12889-015-1843-x.

19. Baxter AJ, Scott KM, Vos T, Whiteford HA. Global prevalence of anxiety disorders: a systematic review and meta-regression. Psychol Med. 2013;43(5): 897-910. https://doi.org/10.1017/s003329171200147x.

20. American Psychiatric Association. Diagnostic and statistical manual of mental disorders. 5th ed. Washington, DC: American Psychiatric Association; 2013

21. Spielberger CD. Manual for the state-trait anxiety inventory. Palo Alto: Consulting Psychologist Press; 1983.

22. Bandelow B, Michaelis S. Epidemiology of anxiety disorders in the $21 \mathrm{st}$ century. Dialogues Clin Neurosci. 2015;17(3):327-35. https://doi.org/10.1016/ j.mppsy.2007.01.007

23. Kessler RC, Berglund P, Demler O, Jin R, Merikangas KR, Walters EE. Lifetime prevalence and age-of-onset distributions of DSM-IV disorders in the National Comorbidity Survey Replication. Arch Gen Psychiatry. 2005:62(6): 593-602. https://doi.org/10.1001/archpsyc.62.6.593. 
24. Boyko EJ, Seelig AD, Jacobson IG, Hooper TI, Smith B, Smith TC, CrumCianflone NF. Millennium cohort study team. Sleep characteristics, mental health, and diabetes risk: a prospective study of U.S. military service members in the millennium cohort study. Diabetes Care. 2013;36(10):315461. https://doi.org/10.2337/dc13-0042

25. Lambiase M, Kubzansky LD, Thurston RC. Prospective study of anxiety and incident stroke. Stroke. 2014;45(2):438-43. https:/doi.org/10.1161/strokeaha.113.003741.

26. Roest AM, Martens EJ, de Jonge P, Denollet J. Anxiety and risk of incident coronary heart disease: a meta-analysis. J Am Coll Cardiol. 2010;56(1):38-46. https://doi.org/10.1016/j.jacc.2010.03.034.

27. Scott KM. Depression, anxiety and incident cardiometabolic diseases. Curr Opin Psychiatry. 2014;27(4):289-93. https://doi.org/10.1097/yco. 0000000000000067.

28. Rebar AL, Stanton R, Geard D, Short C, Duncan MJ, Vandelanotte C. A metameta-analysis of the effect of physical activity on depression and anxiety in non-clinical adult populations. Health Psychol Rev. 2015;9(3):366-78. https:// doi.org/10.1080/17437199.2015.1022901

29. Ströhle A. Physical activity, exercise, depression and anxiety disorders. J Neural Transm. 2009;1 16(6):777-84. https://doi.org/10.1007/s00702-008-0092-x

30. Salmon P. Effects of physical exercise on anxiety, depression, and sensitivity to stress: a unifying theory. Clin Psychol Rev. 2001;21(1):33-61. https://doi. org/10.1016/S0272-7358(99)00032-X.

31. Christianson JP, Ragole T, Amat J, Greenwood BN, Strong PV, Paul ED, Fleshner M, Watkins LR, Maier SF. 5-hydroxytryptamine 2 receptors in the basolateral amygdala are involved in the expression of anxiety after uncontrollable traumatic stress. Biol Psychiatry. 2010;67(4):339-45. https:// doi.org/10.1016/j.biopsych.2009.09.011.

32. Greenwood BN, Strong PV, Loughridge AB, Day HE, Clark PJ, Mika A, Hellwinkel JE, Spence KG, Fleshner M. 5-HT2C receptors in the basolateral amygdala and dorsal striatum are a novel target for the anxiolytic and antidepressant effects of exercise. PLoS One. 2012;7(9):e46118. https://doi. org/10.1371/journal.pone.0046118.

33. Kraut R, Kiesler S, Boneva B, Cummings J, Helgeson V, Crawford A. Internet paradox revisited. J Soc Issues. 2002;58(1):49-74. https://doi.org/10.1111/ 1540-4560.00248.

34. Atkin AJ, Adams E, Bull FC, Biddle SJ. Non-occupational sitting and mental well-being in employed adults. Ann Behav Med. 2012;43(2):181-8. https:// doi.org/10.1007/s12160-011-9320-y.

35. Smith L, Hamer M. Sedentary behaviour and psychosocial health across the life course. In: Leitzmann MF, Jochem C, Schmid D, editors. Sedentary behaviour epidemiology. Cham: Springer; 2018. p. 311-8. https://doi.org/10. 1007/978-3-319-61552-3_12.

36. Chastin SF, Palarea-Albaladejo J, Dontje ML, Skelton DA. Combined effects of time spent in physical activity, sedentary behaviors and sleep on obesity and cardio-metabolic health markers: a novel compositional data analysis approach. PLoS One. 2015;10(10):e0139984. https://doi.org/10.1371/journal. pone.0139984.

37. O'Donoghue G, Perchoux C, Mensah K, Lakerveld J, van der Ploeg H, Bernaards C, Chastin SF, Simon C, O'Gorman D, Nazare JA, DEDIPAC Consortium. A systematic review of correlates of sedentary behaviour in adults aged 18-65 years: a socio-ecological approach. BMC Public Health. 2016;16:163. https://doi.org/10.1186/s12889-016-2841-3.

38. Stierlin AS, De Lepeleere S, Cardon G, Dargent-Molina P, Hoffmann B, Murphy MH, Kennedy A, O'Donoghue G, Chastin SF, De Craemer M, DEDIPAC Consortium. A systematic review of determinants of sedentary behaviour in youth: a DEDIPAC-study. Int J Behav Nutr Phys Act. 2015;12: 133. https://doi.org/10.1186/s12966-015-0291-4.

39. Chastin SF, De Craemer M, Lien N, Bernaards C, Buck C, Oppert JM, Nazare JA, Lakerveld J, O'Donoghue G, Holdsworth M, et al. The SOS-framework (Systems of Sedentary behaviours): an international transdisciplinary consensus framework for the study of determinants, research priorities and policy on sedentary behaviour across the life course: a DEDIPAC-study. Int J Behav Nutr Phys Act. 2016;13:83. https://doi.org/10.1186/s12966-016-0409-3.

40. Costigan SA, Barnett L, Plotnikoff RC, Lubans DR. The health indicators associated with screen-based sedentary behavior among adolescent girls: a systematic review. J Adolesc Health. 2013;52(4):382-92. https://doi.org/10. 1016/j.jadohealth.2012.07.018.

41. Edwards MK, Loprinzi PD. Experimentally increasing sedentary behavior results in increased anxiety in an active young adult population. J Affect Disord. 2016;204:166-73. https://doi.org/10.1016/j. jad.2016.06.045.
42. Motl RW, McAuley E. Physical activity, disability, and quality of life in older adults. Phys Med Rehabil Clin N Am. 2010;21(2):299-308. https://doi.org/10. 1016/j.pmr.2009.12.006.

43. Prince SA. Interventions directed at reducing sedentary behaviour in persons with pre-existing disease or disability. In: Leitzmann MF, Jochem C, Schmid D, editors. Sedentary behaviour epidemiology. Cham: Springer; 2018. p. 471-85. https://doi.org/10.1007/978-3-319-61552-3_20.

44. Copeland JL, Ashe MC, Biddle SJ, Brown WJ, Buman MP, Chastin S, Gardiner PA, Inoue S, Jefferis BJ, Oka K, et al. Sedentary time in older adults: a critical review of measurement, associations with health, and interventions. $\mathrm{Br} J$ Sports Med. 2017;51(21):1539. https://doi.org/10.1136/bjsports-2016-097210.

45. Moher D, Liberati A, Tetzlaff J, Altman DG, PRISMA Group. Preferred reporting items for systematic reviews and meta-analyses: the PRISMA statement. PLoS Med. 2009;6(7):e1000097. https://doi.org/10.1371/journal. pmed.1000097.

46. Kmet LM, Lee RC, Cook LS. Standard quality assessment criteria for evaluating primary research papers from a variety of fields. Edmonton: Alberta Heritage Foundation for Medical Research (AHFMR); 2004. Available from: http://www.ihe.ca/advanced-search/standard-quality-assessmentcriteria-for-evaluating-primary-research-papers-from-a-variety-of-fields

47. Jüni $P$, Holenstein F, Sterne J, Bartlett $C$, Egger M. Direction and impact of language bias in meta-analyses of controlled trials: empirical study. Int J Epidemiol. 2002;31(1):115-23. https://doi.org/10.1093/ije/31.1.115.

48. Higgins JPT, Green S, editors. Cochrane handbook for systematic reviews of interventions version 5.1.0 [updated March 2011]. London: The Cochrane Collaboration; 2011. Available from: http://handbook-5-1.cochrane.org/

49. Higgins JPT, Green S, editors. Cochrane handbook for systematic reviews of interventions. Chichester: Wiley; 2008.

50. Sedentary Behaviour Research Network. Letter to the editor: standardized use of the terms "sedentary" and "sedentary behaviours". Appl Physiol Nutr Metab. 2012;37(3):540-2. https://doi.org/10.1139/h2012-024.

51. Boberska M, Szczuka Z, Kruk M, Knoll N, Keller J, Hohl DH, Luszczynska A Sedentary behaviours and health-related quality of life. A systematic review and meta-analysis. Health Psychol Rev. 2018;12(2):195-210. https://doi.org/ 10.1080/17437199.2017.1396191.

52. Luszczynska A, Pawlowska I, Cieslak R, Knoll N, Scholz U. Social support and quality of life among lung cancer patients: a systematic review. Psychooncology. 2013;22(10):2160-8. https://doi.org/10.1002/pon.3218.

53. Sallis JF, Prochaska JJ, Taylor WC. A review of correlates of physical activity of children and adolescents. Med Sci Sports Exerc. 2000;32(5):963-75. https://doi.org/10.1097/00005768-200005000-00014.

54. Borenstein $M$, Hedges L, Higgins J, Rothstein H. Comprehensive metaanalysis version 2. Englewood: Biostat; 2005.

55. Bax L, Yu LM, Ikeda N, Moons KG. A systematic comparison of software dedicated to meta-analysis of causal studies. BMC Med Res Methodol. 2007; 7:40. https://doi.org/10.1186/1471-2288-7-40

56. Borenstein $M$, Hedges LV, Higgins JP, Rothstein HR. Introduction to metaanalysis. Chichester: Wiley; 2011. https://doi.org/10.1002/9780470743386.

57. Hunter JE, Schmidt FL. Methods of meta-analysis: correcting error and bias in research findings. Thousand Oaks: SAGE Publications; 2004. https://doi. org/10.4135/9781483398105.

58. Hedges LV, Pigott TD. The power of statistical tests for moderators in metaanalysis. Psychol Methods. 2004;9(4):426-45. https://doi.org/10.1037/1082989X.9.4.426.

59. Asfour L, Koussa M, Perrino T, Stoutenberg M, Prado G. The association of organized and unorganized physical activity and sedentary behavior with internalizing and externalizing symptoms in Hispanic adolescents. Child Adolesc Mental Health. 2015;21(2):109-14. https://doi.org/10.1111/camh. 12139.

60. Achenbach TM. Manual for the child behavior checklist/4-18 and 1991 profile. Burlington: Department of Psychiatry, University of Vermont; 1991.

61. * Asztalos M, Cardon G, De Bourdeaudhuij I, De Cocker K. Cross-sectional associations between sitting time and several aspects of mental health in Belgian adults. J Phys Act Health. 2015;12(8):1112-8. https://doi.org/10.1123/ jpah.2013-0513.

62. Hagströmer M, Oja P, Sjöström M. The international physical activity questionnaire (IPAQ): a study of concurrent and construct validity. Public Health Nutr. 2006;9(6):755-62.

63. Arrindell WA, Ettema JHM. Symptom Checklist-90, SCL-90, Handleinding bij een multidimensionele psychopathologie-indicator. Swets Test Services: Lisse; 1986. 
64. * Bampton EA, Johnson ST, Vallance JK. Profiles of resistance training behavior and sedentary time among older adults: associations with healthrelated quality of life and psychosocial health. Prev Med Rep. 2015;2:773-6. https://doi.org/10.1016/j.pmedr.2015.08.017.

65. Kroenke K, Spitzer RL, Williams JB, Monahan PO, Löwe B. Anxiety disorders in primary care: prevalence, impairment, comorbidity, and detection. Ann Intern Med. 2007;146(5):317-25. https://doi.org/10.7326/0003-4819-146-5200703060-00004

66. Cao H, Qian Q, Weng T, Yuan C, Sun Y, Wang H, Tao F. Screen time, physical activity and mental health among urban adolescents in China. Prev Med. 2011;53(4-5):316-20. https://doi.org/10.1016/j.ypmed.2011.09.002.

67. Birmaher B, Brent DA, Chiappetta L, Bridge J, Monga S, Baugher M. Psychometric properties of the screen for child anxiety related emotional disorders (SCARED): a replication study. J Am Acad Child Adolesc Psychiatry. 1999;38(10):1230-6. https://doi.org/10.1097/00004583-199910000-00011.

68. de Wit L, van Straten A, Lamers F, Cuijpers P, Penninx B. Are sedentary television watching and computer use behaviors associated with anxiety and depressive disorders? Psychiatry Res. 2011;186(2-3):239-43. https://doi. org/10.1016/j.psychres.2010.07.003.

69. Wittchen HU. Reliability and validity studies of the WHO-composite international diagnostic interview (CIDI): a critical review. J Psychiatr Res. 1994;28(1):57-84. https://doi.org/10.1016/0022-3956(94)90036-1.

70. de Wit L, Jelsma JG, van Poppel MN, Bogaerts A, Simmons D, Desoye G, Corcoy R, Kautzky-Willer A, Harreiter J, van Assche A, et al. Physical activity, depressed mood and pregnancy worries in European obese pregnant women: results from the DALI study. BMC Pregnancy Childbirth. 2015;15: 158. https://doi.org/10.1186/s12884-015-0595-z.

71. Green JM, Kafetsios K, Statham HE, Snowdon CM. Factor structure, validity and reliability of the Cambridge worry scale in a pregnant population. J Health Psychol. 2003;8(6):753-64. https://doi.org/10.1177/ 13591053030086008.

72. Dillon CB, McMahon E, O'Regan G, Perry IJ. Associations between physical behaviour patterns and levels of depressive symptoms, anxiety and wellbeing in middle-aged adults: a cross-sectional study using isotemporal substitution models. BMJ Open. 2018;8(1):e018978. https://doi.org/10.1136/ bmjopen-2017-018978.

73. Zigmond AS, Snaith RP. The hospital anxiety and depression scale. Acta Psychiatr Scand. 1983;67(6):361-70. https://doi.org/10.1111/j.1600-0447.1983. tb09716.x

74. Schneider PL, Crouter SE, Lukajic O, Bassett DR Jr. Accuracy and reliability of 10 pedometers for measuring steps over a 400-m walk. Med Sci Sports Exerc. 2003:35(10):1779-84. https://doi.org/10.1249/01.mss.0000089342.96098.c4.

75. Norman SB, Cissell SH, Means-Christensen AJ, Stein MB. Development and validation of an overall anxiety severity and impairment scale (OASIS). Depress Anxiety. 2006:23(4):245-9. https://doi.org/10.1002/da.20182.

76. * Feng Q, Zhang QL, Du Y, Ye YL, He QQ. Associations of physical activity, screen time with depression, anxiety and sleep quality among Chinese college freshmen. PLoS One. 2014;9(6):e100914. https://doi.org/10.1371/ journal.pone.0100914.

77. Zung WW. A rating instrument for anxiety disorders. Psychosomatics. 1971; 12(6):371-9. https://doi.org/10.1016/s0033-3182(71)71479-0.

78. Gaskin CJ, Craike M, Mohebbi M, Salmon J, Courneya KS, Broadbent S, Livingston PM. Associations of objectively measured moderate-to-vigorous physical activity and sedentary behavior with quality of life and psychological well-being in prostate cancer survivors. Cancer Causes Control. 2016;27(9):1093-103. https://doi.org/10.1007/s10552-016-0787-5.

79. Roth AJ, Rosenfeld B, Kornblith AB, Gibson C, Scher HI, Curley-Smart T, Holland JC, Breitbart W. The memorial anxiety scale for prostate cancer: validation of a new scale to measure anxiety in men with with prostate cancer. Cancer. 2003;97(11):2910-8. https://doi.org/10.1002/cncr.11386.

80. * Gibson AM, Muggeridge DJ, Hughes AR, Kelly L, Kirk A. An examination of objectively-measured sedentary behavior and mental well-being in adults across week days and weekends. PLoS One. 2017;12(9):e0185143. https:// doi.org/10.1371/journal.pone.0185143.

81. * Gunnell KE, Flament MF, Buchholz A, Henderson KA, Obeid N, Schubert N, Goldfield GS. Examining the bidirectional relationship between physical activity, screen time, and symptoms of anxiety and depression over time during adolescence. Prev Med. 2016;88:147-52. https://doi.org/10.1016/j. ypmed.2016.04.002

82. March JS, Parker JD, Sullivan K, Stallings P, Conners CK. The multidimensional anxiety scale for children (MASC): factor structure, reliability, and validity. J Am Acad Child Adolesc Psychiatry. 1997;36(4):55465. https://doi.org/10.1097/00004583-199704000-00019.

83. Hiles SA, Lamers F, Milaneschi Y, Penninx BWJH. Sit, step, sweat: longitudinal associations between physical activity patterns, anxiety and depression. Psychol Med. 2017:47(8):1466-77. https://doi.org/10.1017/ S0033291716003548.

84. Beck AT, Epstein N, Brown G, Steer RA. An inventory for measuring clinical anxiety: psychometric properties. J Consult Clin Psychol. 1988;56(6):893-7. https://doi.org/10.1037/0022-006X.56.6.893.

85. * Janney CA, Ganguli R, Richardson CR, Holleman RG, Tang G, Cauley JA, Kriska AM. Sedentary behavior and psychiatric symptoms in overweight and obese adults with schizophrenia and schizoaffective disorders (WAIST study). Schizophr Res. 2013;145(1-3):63-8. https://doi.org/10.1016/j.schres. 2013.01.010

86. Kay SR, Fiszbein A, Opler LA. The positive and negative syndrome scale (PANSS) for schizophrenia. Schizophr Bull. 1987;13(2):261-76. https://doi.org/ 10.1093/schbul/13.2.261.

87. Kovess-Masfety V, Keyes K, Hamilton A, Hanson G, Bitfoi A, Golitz D, Koç C, Kuijpers $\mathrm{R}$, Lesinskiene S, Mihova $Z$, et al. Is time spent playing video games associated with mental health, cognitive and social skills in young children? Soc Psychiatry Psychiatr Epidemiol. 2016;51(3):349-57. https://doi.org/10. 1007/s00127-016-1179-6.

88. Kuijpers RC, Otten R, Vermulst AA, Pez O, Bitfoi A, Carta M, Goelitz D, Keyes K, Koç C, Lesinskiene $S$, et al. Reliability, factor structure, and measurement invariance of the Dominic interactive across European countries: crosscountry utility of a child mental health self-report. Psychol Assess. 2016; 28(5):539-48. https://doi.org/10.1037/pas0000139.

89. * Kroeders R, Bernhardt J, Cumming T. Physical inactivity, depression and anxiety in acute stroke. Int J Therap Rehabil. 2013;20(6):289-93. https://doi. org/10.12968/ijtr.2013.20.6.289

90. Snaith RP, Constantopoulos AA, Jardine MY, McGuffin P. A clinical scale for the self-assessment of irritability. Br J Psychiatry. 1978;132:164-71. https:// doi.org/10.1192/bjp.132.2.164.

91. * Liu M, Ming Q, Yi J, Wang X, Yao S. Screen time on school days and risks for psychiatric symptoms and self-harm in mainland Chinese adolescents. Front Psychol. 2016:7:574. https://doi.org/10.3389/fpsyg.2016.00574.

92. Brener ND, Kann L, McManus T, Kinchen SA, Sundberg EC, Ross JG. Reliability of the 1999 youth risk behavior survey questionnaire. J Adolesc Health. 2002;31(4):336-42. https://doi.org/10.1016/s1054-139x(02)00339-7.

93. Yao S, Zou T, Zhu X, Abela JR, Auerbach RP, Tong X. Reliability and validity of the Chinese version of the multidimensional anxiety scale for children among Chinese secondary school students. Child Psychiatry Hum Dev. 2007:38(1):1-16. https://doi.org/10.1007/s10578-006-0039-0.

94. * Maras D, Flament MF, Murray M, Buchholz A, Henderson KA, Obeid N, Goldfield GS. Screen time is associated with depression and anxiety in Canadian youth. Prev Med. 2015;73:133-8. https://doi.org/10.1016/j.ypmed. 2015.01.029.

95. Mesquita R, Meijer K, Pitta F, Azcuna H, Goërtz YMJ, Essers JMN, Wouters EFM, Spruit MA. Changes in physical activity and sedentary behaviour following pulmonary rehabilitation in patients with COPD. Respir Med. 2017; 126:122-9. https://doi.org/10.1016/j.rmed.2017.03.029.

96. * Opdenacker J, Boen F. Effectiveness of face-to-face versus telephone support in increasing physical activity and mental health among university employees. J Phys Act Health. 2008;5(6):830-43. https://doi.org/10.1123/jpah. 5.6.830.

97. * Padmapriya N, Bernard JY, Liang S, Loy SL, Shen Z, Kwek K, Godfrey KM, Gluckman PD, Chong YS, Saw SM, et al. Association of physical activity and sedentary behavior with depression and anxiety symptoms during pregnancy in a multiethnic cohort of Asian women. Arch Womens Ment Health. 2016;19(6):1119-28. https://doi.org/10.1007/s00737-016-0664-y.

98. * Park S, Thøgersen-Ntoumani C, Ntoumanis N, Stenling A, Fenton SA Veldhuijzen van Zanten JJ. Profiles of physical function, physical activity, and sedentary behavior and their associations with mental health in residents of assisted living facilities. Appl Psychol Health Well Being. 2017;9(1):60-80. https://doi.org/10.1111/aphw.12085.

99. * Rebar AL, Vandelanotte C, Van Uffelen J, Short C, Duncan MJ. Associations of overall sitting time and sitting time in different contexts with depression, anxiety, and stress symptoms. Ment Health and Phys Act. 2014;7(2):105-10. https://doi.org/10.1016/j.mhpa.2014.02.004.

100. Chau JY, van der Ploeg HP, Dunn S, Kurko J, Bauman AE. A tool for measuring workers' sitting time by domain: the workforce sitting 
questionnaire. Br J Sports Med. 2011;45(15):1216-22. https://doi.org/10.1136/ bjsports-2011-090214.

101. Henry JD, Crawford JR. The short-form version of the depression anxiety stress scales (DASS-21): construct validity and normative data in a large nonclinical sample. Br J Clin Psychol. 2005;44(2):227-39. https://doi.org/10.1348/ $014466505 \times 29657$.

102. Sanchez-Villegas A, Ara I, Guillén-Grima F, Bes-Rastrollo M, VaroCenarruzabeitia JJ, Martínez-González MA. Physical activity, sedentary index, and mental disorders in the SUN cohort study. Med Sci Sports Exerc. 2008; 40(5):827-34. https://doi.org/10.1249/MSS.0b013e31816348b9.

103. * Straker L, Smith A, Hands B, Olds T, Abbott R. Screen-based media use clusters are related to other activity behaviours and health indicators in adolescents. BMC Public Health. 2013;13:1174. https://doi.org/10.1186/14712458-13-1174.

104. Ridley K, Olds TS, Hill A. The multimedia activity recall for children and adolescents (MARCA): development and evaluation. Int J Behav Nutr Phys Act. 2006;3:10. https://doi.org/10.1186/1479-5868-3-10.

105. * Teychenne M, Hinkley T. Associations between screen-based sedentary behaviour and anxiety symptoms in mothers with young children. PLoS One. 2016;11(5):e0155696. https://doi.org/10.1371/journal.pone.0155696.

106. Bjelland I, Dahl AA, Haug T, Neckelmann D. The validity of the hospital anxiety and depression scale. An updated literature review. J Psychosom Res. 2002;52(2):69-77. https://doi.org/10.1016/s0022-3999(01)00296-3.

107. Uijtdewilligen L, Singh AS, Twisk JW, Koppes LL, van Mechelen W, Chinapaw MJ. Adolescent predictors of objectively measured physical activity and sedentary behaviour at age 42: the Amsterdam Growth and Health Longitudinal Study (AGAHLS). Int J Behav Nutr Phys Act. 2011;8:107. https:// doi.org/10.1186/1479-5868-8-107.

108. Hermans HJM. Handleiding Prestatie Motivatie Test voor kinderen 1983 [manual achievement motivation test for children, version 1983]. Amsterdam: Swets \& Zeitlinger; 1983.

109. * Vallance JK, Boyle T, Courneya KS, Lynch BM. Accelerometer-assessed physical activity and sedentary time among colon cancer survivors: associations with psychological health outcomes. J Cancer Surviv. 2015;9(3): 404-11. https://doi.org/10.1007/s11764-014-0409-8.

110. * van Roekel EH, Bours MJ, Breedveld-Peters JJ, Willems PJ, Meijer K, Kant I, van den Brandt PA, Beets GL, Sanduleanu S, Weijenberg MP. Modeling how substitution of sedentary behavior with standing or physical activity is associated with health-related quality of life in colorectal cancer survivors. Cancer Causes Control. 2016;27(4):513-25. https://doi.org/10.1007/s10552016-0725-6.

111. Vancampfort D, Stubbs B, Herring MP, Hallgren M, Koyanagi A. Sedentary behavior and anxiety: association and influential factors among 42,469 community-dwelling adults in six low- and middle-income countries. Gen Hosp Psychiatry. 2018;50:26-32. https://doi.org/10.1016/j.genhosppsych. 2017.09.006

112. Wu X, Tao S, Zhang Y, Zhang S, Tao F. Low physical activity and high screen time can increase the risks of mental health problems and poor sleep quality among Chinese college students. PLoS One. 2015;10(3):e0119607. https://doi.org/10.1371/journal.pone.0119607.

113. Deeks JJ, Higgins JPT, Altman DG. Analysing data and undertaking metaanalyses. In: Higgins JPT, Green S, editors. Cochrane handbook for systematic reviews of interventions. Chichester: Wiley; 2008. https://doi.org/ 10.1002/9780470712184.ch9.

114. Borenstein M, Higgins JP, Hedges LV, Rothstein HR. Basics of meta-analysis: $\mathrm{I}^{2}$ is not an absolute measure of heterogeneity. Res Synth Methods. 2017; 8(1):5-18. https://doi.org/10.1002/jrsm. 1230.

115. Horodyska K, Luszczynska A, van den Berg M, Hendriksen M, Roos G, De Bourdeaudhuij I, Brug J. Good practice characteristics of diet and physical activity interventions and policies: an umbrella review. BMC Public Health. 2015;15:19. https://doi.org/10.1186/s12889-015-1354-9.

116. Banik A, Schwarzer R, Knoll N, Czekierda K, Luszczynska A. Self-efficacy and quality of life among people with cardiovascular diseases: a meta-analysis. Rehabil Psychol. 2018:63(2):295-312. https://doi.org/10.1037/rep0000199.

Ready to submit your research? Choose BMC and benefit from:

- fast, convenient online submission

- thorough peer review by experienced researchers in your field

- rapid publication on acceptance

- support for research data, including large and complex data types

- gold Open Access which fosters wider collaboration and increased citations

- maximum visibility for your research: over $100 \mathrm{M}$ website views per year

At BMC, research is always in progress.

Learn more biomedcentral.com/submissions 